\title{
Article \\ Effect of Seasonal Storage on Single-Stem Bark Extractives of Norway Spruce (Picea abies)
}

\author{
Eelis S. Halmemies ${ }^{1,2, *}$, Hanna E. Brännström ${ }^{1}$, Juha Nurmi ${ }^{1}$, Otto Läspä ${ }^{3}$ and Raimo Alén ${ }^{2}$ \\ 1 Department of Production Systems, Natural Resources Institute Finland (Luke), Teknologiakatu 7, \\ 67100 Kokkola, Finland; hanna.brannstrom@luke.fi (H.E.B.); juha.nurmi@luke.fi (J.N.) \\ 2 Department of Chemistry, University of Jyväskylä, Survontie 9, 40500 Jyväskylä, Finland; raimo.j.alen@jyu.fi \\ 3 School of Engineering and Natural Resources, Oulu University of Applied Sciences, Yliopistonkatu 9, \\ 90570 Oulu, Finland; otto.laspa@oamk.fi \\ * Correspondence: eelis.halmemies@gmail.com
}

Citation: Halmemies, E.S.

Brännström, H.E.; Nurmi, J.; Läspä,

O.; Alén, R. Effect of Seasonal Storage on Single-Stem Bark Extractives of Norway Spruce (Picea abies). Forests 2021, 12, 736. https://doi.org/ $10.3390 /$ f12060736

Academic Editors: Pekka Saranpää and Xiping Wang

Received: 29 April 2021

Accepted: 1 June 2021

Published: 4 June 2021

Publisher's Note: MDPI stays neutral with regard to jurisdictional claims in published maps and institutional affiliations.

Copyright: (C) 2021 by the authors. Licensee MDPI, Basel, Switzerland. This article is an open access article distributed under the terms and conditions of the Creative Commons Attribution (CC BY) license (https:// creativecommons.org/licenses/by/ $4.0 /)$.

\begin{abstract}
Increasing the net value of forestry side-streams has both ecological as well as economic benefits for emerging biorefining industries. Spruce bark represents one of the nature's abundant sources of valuable extractives. In this study, the impact of storage on the quality and quantity of Norway spruce (Picea abies) extractives was examined as a function of storage time, environmental conditions and season (i.e., winter or summer). The bark from stored spruce saw logs was extracted with an accelerated solvent extractor (ASE) at $120^{\circ} \mathrm{C}$ with hexane and water. The produced extracts were analysed qualitatively and quantitatively by gas chromatography with a flame ionisation detector (GC-FID) and high-performance liquid chromatography (HPLC) methods. The total amount of phenolics in the water extracts was evaluated by the Folin-Ciocalteu method, while the carbohydrate and lignin content of the extractive-free bark was estimated by acidic hydrolysis and acidic methanolysis. According to the results, storage season and temperature dramatically influenced both the chemical composition and degradation rate of bark extractives. After a storage period of 24 weeks, the winter-stored saw log bark retained $22 \%$ more hydrophilic extractives than the summer-stored bark. Lipophilic extractives, however, were 14\% higher during the summer. Notably, the average amount of monomeric stilbenoids was $61 \%$ higher during the winter storage period. The initial total phenolic content in the water extracts was significantly higher during winter, but the degradation rate was about equal during winter and summer. The amount of cellulose in dry bark decreased from $17 \%$ to $11 \%$ and from $13 \%$ to $6 \%$ during winter and summer, respectively. By contrast, hemicelluloses increased from $17 \%$ to $26 \%$ and $15 \%$ to $30 \%$ during winter and summer, respectively. Overall, it was demonstrated that the seasonal factors of storage greatly affected the degradation rate of valuable spruce bark extractives, which should be considered in the planning stages of the raw materials procurement chain.
\end{abstract}

Keywords: spruce bark; biomass storage; degradation; extraction; wood extractives; hydrophilic; lipophilic; high-performance liquid chromatography (HPLC); gas chromatography (GC)

\section{Introduction}

In boreal countries, such as Finland and Sweden, the annual consumption of woody biomass and generated by-products, such as bark and logging residues, is substantial. Norway spruce (Picea abies) bark is one of the major contributors in the class of secondary forest resources. The industrial use of spruce pulpwood and saw logs totalled $24.5 \mathrm{Mm}^{3}$ in Finland in 2019 (Luke statistics, 2021). In Finland, this equals 0.9-1.4 Mt/a (d.m.) of spruce bark generated at mills - a value calculated with an estimated average dry density of $380 \mathrm{~kg} / \mathrm{m}^{3}$ [1]. Despite the active promotion of bio-economical solutions, most of the forest industry's by-products are still being burned for heat and power.

The idea of converting these secondary resources into value-added products has genuine potential. Nevertheless, the prerequisite of the valorisation of forestry side-streams 
is that the raw material is handled in a way that does not compromise its quality. The utilisation of valuable extractives and antioxidants from spruce bark is impossible if the raw material is already chemically barren by the time it reaches the end-user. The producers of a given raw material need to make prudent economic and logistical decisions regarding the raw material procurement chain so that the end-user will receive the raw material of the right quality. For this cause, in-depth knowledge and understanding of how the chemical and physical quality of the raw material is affected by different harvesting methods, means of transportation and storage conditions are required.

Softwood bark is known to be an abundant source of phenolic extractives. Norway spruce is rich in polyphenolic extractives and natural antioxidants, such as stilbenes and tannins [2,3]. According to Krogell et al. [3], dry bark spruce extractives (both lipophilic and hydrophilic) account for $38 \%$ by dry weight of inner bark and $22 \%$ of outer bark. In contrast, only $1.0-2.5 \%$ of spruce stemwood comprises extractives [4,5]. Thus, the harvesting of extractives from the bark is a promising prospect. However, bark is a complex mixture of natural polymers and unstable, volatile compounds, and the task of using them on an industrial scale is not a simple one. The production and emission of extractives as a response to various external influences is a constant activity carried out by living tree parenchyma cells, which continues even after tree felling. Moreover, as tree cells' access to nutrients is cut off, the production of new extractives eventually halts, and the remaining extractives' degradation is accelerated [6-9]. Therefore, it may be expected that the raw material losses begin at the harvesting site and continue throughout the procurement and supply chain until the final destination of the material is reached. The chemical composition of the extractives content of trees is likewise expected to change. To capitalise on a product utilising, for example, the stilbene glucosides of spruce bark (piceid, astringin and isorhapontin), understanding both the rate and nature of their degradation is of key importance.

The degradation mechanisms of woody biomass are well known [10], including living cell respiration, biological degradation, thermo-chemical oxidation reactions and moisture evaporation. Thermal degradation and auto-oxidation reactions are more influential in the pile storage of smaller particle-sized material, such as wood chips [11]. In the storage of wood logs, extractives fraction is mainly affected by the evaporation of volatile terpenoids [12,13], the hydrolysis of glycerides and waxes by plant enzymes and the activity of wood-colonising bacteria and fungi [9,14-16] through oxidative and polymerisation reactions [9], the photodegradation of phenolics [17-19] and the leaching of hydrophilic compounds by contact with water [20-23]. Thus, ambient conditions, such as the level of ultraviolet (UV) light, moisture, temperature and wind, are key variables for understanding and explaining the degradation rate of individual extractives compounds during storage. For example, moist storage conditions increase hydrolysis and leaching, while high temperatures and UV light increase photodegradation and polymerisation reactions [10].

Only a few older reports focus on conifer bark storage [11,24], although a recent interest in these studies can be observed [25-27]. However, most of these studies deal with only debarked bark stored in piles, whereas the storage of bark intact on saw logs is less researched [25]. The scope of many storage studies regarding the extractives content of bark or wood has been limited to looking at the amount of total dissolved solids (TDS) and larger extractives groups. In contrast, detailed studies of the degradation pattern of individual extractives are difficult to come across. Many storage studies are also limited in that, by having a single storage setup, they cannot take into consideration the seasonal effects of storage. Our experiment was conducted to fill this gap and provide easily accessible information useful in valorising bark for extractives-based products.

Our experiment aimed to study primarily the behaviour of extractives, carbohydrates and lignin content of saw log bark exposed to outdoor conditions as a function of season and storage time. The spruce bark samples were taken at the beginning of the experiment and after 4, 12 and 24 weeks. Duplicate experiments were conducted-one during the 
winter and one during the summer. Environmental conditions were gathered from the data provided by the Finnish Meteorological Institute [28].

It was concluded that the storage conditions significantly affected especially the content of hydrophilic extractives present in the bark, depending on the storage season. The hydrophilic extractives were found to be $22 \%$ more abundant in the bark stored during winter. The level of hydrophilic extractives remained high up to 12 weeks of storage during winter. The storing of bark intact on saw logs appeared to reduce the degradation of extractives and carbohydrates significantly compared to conventional pile storage of debarked bark. Based on the research, it seemed advisable that in the procurement chain of saw logs, if bark is to be utilised for its extractives content, to avoid unnecessary degradation, debarking should occur at the last possible moment.

\section{Materials and Methods}

\subsection{Storage Setups and Sampling}

The experimental setups for the Norway spruce bark winter and summer storage studies were constructed on 7 February 2017 and 29 May 2017, in Kälviä, Western Finland, respectively. Two identical experimental setups were established to study the seasonal effect of storage on the behaviour of extractives. Freshly felled trees were bucketed to saw logs and placed on a frame platform made from logs to keep them off the ground (Figure 1a) and prevent them from being buried under snow during winter or covered by vegetation during summer.

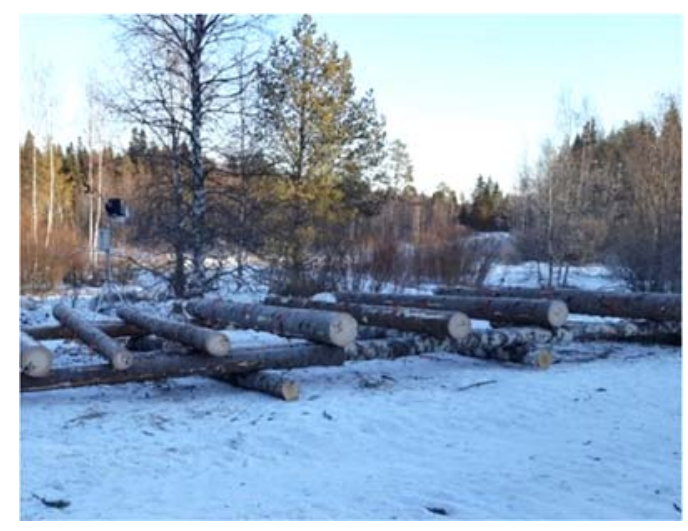

(a)

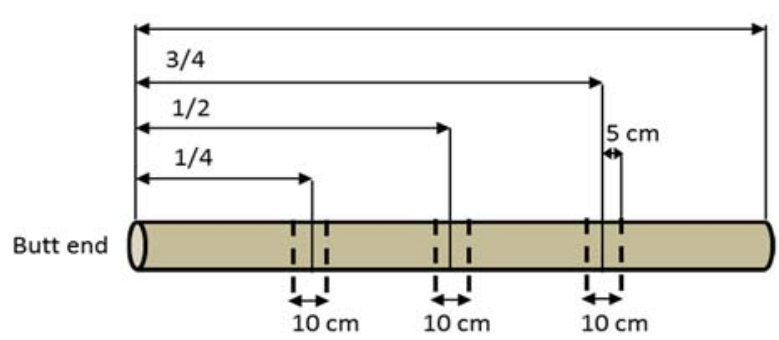

(b)

Figure 1. (a) The setup for the saw log storage study. The image was taken at the beginning of the winter study. (b) Figure indicating the location of the three sample discs cut from each sample log.

For each of the trees used in the storage study, the tree's height, diameter at breast height and age of the tree were measured, as listed in Table 1. The sample discs for the calculation of tree age were cut from the remaining stumps. The sample logs were bucked to approximately $4.5 \mathrm{~m}$ long. The sampling frequency was (in addition to a zero-sample) after 4,12 and 24 weeks. Because the logs' chemical composition changes from the butt end towards the top, three $10 \mathrm{~cm}$ discs were cut from each log (Figure $1 \mathrm{~b}$ ) to yield a more chemically uniform sample. Samples were taken from two saw logs during each sampling. The discs were then debarked manually.

\subsection{The Average Temperature and Precipitation of the Sampling Location}

The average temperatures and the amount of rain at the sampling location (Western Finland, Ostrobothnia region near Kokkola [ $\left.63^{\circ} 54^{\prime} 44.03^{\prime \prime} \mathrm{N}, 23^{\circ} 25^{\prime} 17.0^{\prime \prime} \mathrm{E}\right]$ ) were evaluated by utilising the $10 \mathrm{~m} \times 10 \mathrm{~m}$ scale meteorological data provided by the Finnish Meteorological Institute [28]. Data used were the daily average temperatures $\left({ }^{\circ} \mathrm{C}\right)$ and the daily rain (mm) amounts from 7 February 2017 to 13 November 2017. The data are presented in 
Figure 2. There was an average difference of $5.7^{\circ} \mathrm{C}$ during winter and summer storage; the bark in summer storage experienced a decrease in temperature starting from around $10{ }^{\circ} \mathrm{C}$, rising to $15^{\circ} \mathrm{C}$ after 4 weeks and ending at $0{ }^{\circ} \mathrm{C}$ at 24 weeks, while the bark in winter storage experienced a constant increase in temperature from around $-5^{\circ} \mathrm{C}$ and ending at $15^{\circ} \mathrm{C}$ at 24 weeks. The average weekly amount of rain was $9.5 \mathrm{~mm}$ during the winter storage and $11.6 \mathrm{~mm}$ during the summer storage.

Table 1. Measurements taken from the saw logs used for the storage studies. Two log samples were taken at each sampling time.

\begin{tabular}{|c|c|c|c|c|c|c|c|c|c|c|c|c|}
\hline & \multirow{3}{*}{$\begin{array}{c}\text { Storage Sample } \\
\text { weeks }\end{array}$} & \multirow{3}{*}{$\begin{array}{c}\text { Tree Age } \\
\text { years }\end{array}$} & \multirow{3}{*}{$\begin{array}{c}\text { Tree Height } \\
\mathrm{dm}\end{array}$} & \multirow{2}{*}{\multicolumn{2}{|c|}{ D1.3m }} & \multirow{3}{*}{$\begin{array}{c}\text { Log Length } \\
\mathrm{dm}\end{array}$} & \multicolumn{6}{|c|}{ Log Diameter } \\
\hline & & & & & & & \multicolumn{2}{|c|}{ Butt End } & \multicolumn{2}{|c|}{ Middle } & \multicolumn{2}{|c|}{ Top } \\
\hline & & & & $\mathrm{mm}$ & $\mathrm{mm}$ & & $\mathrm{mm}$ & $\mathrm{mm}$ & $\mathrm{mm}$ & $\mathrm{mm}$ & $\mathrm{mm}$ & $\mathrm{mm}$ \\
\hline \multirow{8}{*}{ 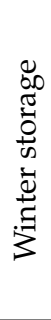 } & 0 & 119 & 225 & 362 & 345 & 47 & 310 & 319 & 290 & 306 & 261 & 270 \\
\hline & 0 & 96 & 223 & 321 & 272 & 46 & 273 & 255 & 242 & 249 & 215 & 227 \\
\hline & 4 & 97 & 210 & 301 & 299 & 47 & 260 & 258 & 234 & 238 & 216 & 219 \\
\hline & 4 & 94 & 215 & 280 & 277 & 46 & 282 & 279 & 257 & 263 & 235 & 232 \\
\hline & 12 & 73 & 206 & 260 & 263 & 46 & 234 & 226 & 204 & 207 & 191 & 185 \\
\hline & 12 & 56 & 213 & 362 & 362 & 45 & 317 & 305 & 282 & 290 & 254 & 262 \\
\hline & 24 & 96 & 224 & 323 & 341 & 46 & 264 & 269 & 238 & 244 & 207 & 210 \\
\hline & 24 & 78 & 256 & 305 & 299 & 46 & 282 & 281 & 256 & 261 & 247 & 240 \\
\hline \multirow{8}{*}{ 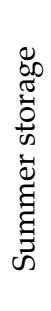 } & 0 & 67 & 243 & 307 & 310 & 48 & 279 & 272 & 262 & 254 & 243 & 237 \\
\hline & 0 & 70 & 245 & 362 & 357 & 44 & 310 & 311 & 300 & 291 & 292 & 289 \\
\hline & 4 & 100 & 270 & 392 & 399 & 43 & 350 & 342 & 324 & 326 & 313 & 305 \\
\hline & 4 & 95 & 255 & 360 & 364 & 49 & 303 & 310 & 281 & 284 & 254 & 256 \\
\hline & 12 & 94 & 260 & 326 & 326 & 47 & 284 & 290 & 274 & 267 & 290 & 246 \\
\hline & 12 & 58 & 225 & 304 & 300 & 48 & 256 & 239 & 225 & 219 & 206 & 199 \\
\hline & 24 & 89 & 262 & 359 & 358 & 46 & 329 & 318 & 316 & 305 & 290 & 284 \\
\hline & 24 & 93 & 252 & 285 & 278 & 48 & 271 & 260 & 246 & 242 & 226 & 224 \\
\hline
\end{tabular}

\subsection{Bark Initial Moisture Content}

The average moisture contents in the bark samples at each sampling time are presented in Figure 2. The average moisture content for bark from the winter setup was $51.8 \%$ and from the summer setup $48.8 \%$, indicating a slight decrease during the warm summer months. Also, there was an increase towards the end of the year (from September to December) as the weather cooled and the average amount of rain increased. This result concurs with Nurmi and Hillebrand [29] regarding the moisture content of harvest residues stored in uncovered piles. They found that the lowest moisture content was observed in winter-stored material at the end of the summer, and the moisture content increased if storage continued until the following winter.

\subsection{Pretreatment and Basic Characterisation of Bark Samples}

The discs' bark was removed manually and then ground into smaller particle sizes with a Jens Algol System woodchipper. The moisture content of the fresh bark samples was determined by a standard method [30]. The samples were dried at $105^{\circ} \mathrm{C}$ in atmospheric air until a constant mass was achieved. The measurements were performed in duplicate. Evaluation of the relationship between log height and the bark's extractives content was outside of the scope of this study. Thus, the bark from the three discs was mixed to form a single sample representing the whole log. For chemical analysis, the samples from the two different logs from each sampling time were also mixed.

The bark was lyophilised (for at least three days) and ground with a Retsch SM 100 cutting laboratory mill (Retsch $\mathrm{GmbH}$, Haan, Germany) equipped with a bottom sieve with trapezoidal holes (perforation size $<1.0 \mathrm{~mm}$ ) for chemical analysis. Samples were stored in a frozen state $\left(<-20^{\circ} \mathrm{C}\right)$. The dry matter content of each lyophilised bark sample was determined by drying $1 \mathrm{~g}$ of bark powder at $105^{\circ} \mathrm{C}$ in an oven overnight in tared crucibles. 

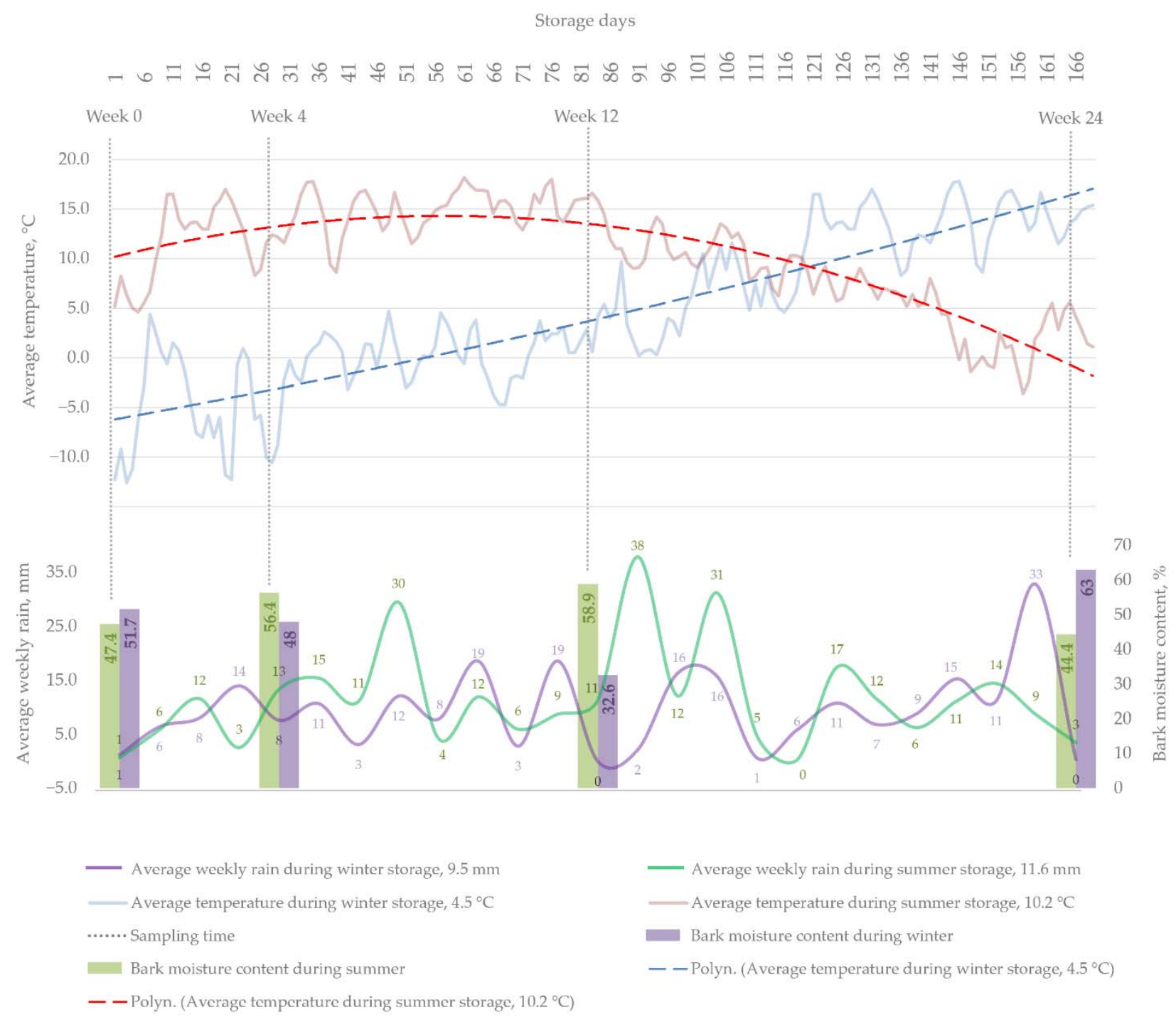

Figure 2. Average ambient temperatures and weekly amounts of rain during winter and summer storage, and the initial moisture content of bark samples at each sampling point. The sampling points (weeks $0,4,12$ and 24 ) are indicated by vertical dotted lines.

\subsection{Chemicals}

The solvents used in the sample preparation of extractives were analytical grade acetone (BDH), high-performance liquid chromatography (HPLC)-grade hexane (VWR), methyl tert-butyl ether (MTBE, Lab-Scan), pyridine (BDH), 95\% ethanol (EtOH, $>94 \%$, ETAX A, Altia Corporation), $n$-butanol (Merck), HPLC-grade methanol (MeOH, Merck), diethyl ether $(\geq 99.8 \%$, Sigma) and HPLC-grade acetonitrile (Fischer Chemicals). Bis(trimethylsilyl) trifluoroacetamide (BSTFA) and trimethylchlorosilane (TMCS) used for silylation came from Regis Technologies.

The compounds used as internal standards in the gas chromatography (GC) analysis of extractives were heneicosanoic acid (99\%, Sigma) and betulinol ( $\geq 98 \%$, Sigma), cholesteryl margarate ( $\geq 97 \%$, TCI America) and 1,3-dipalmitoyl-2-oleylglyserol ( $\geq 99 \%$, Sigma). The standard used for the quantitative analysis of stilbenes with HPLC was trans-piceid (99\%, PhytoLab). $\mathrm{KOH}\left(85 \%\right.$, Merck), $\mathrm{NaOH}(>98 \%, \mathrm{VWR}), \mathrm{HCl}(37 \%, \mathrm{VWR})$ and $\mathrm{Na}_{2} \mathrm{CO}_{3}(\geq 99.8$, Sigma) and sulphuric acid (95-97\%, Sigma) and bromocresol green ( $>95 \%$, Sigma) were also used in the analysis. 


\subsection{Extraction of Bark Samples}

The extractions of bark samples were done by a Dionex accelerated solvent extractor (ASE) 100 instrument using hexane and water as solvents for lipophilic and hydrophilic extractives, respectively. The extraction temperature was $120^{\circ} \mathrm{C}$, static extraction time $10 \mathrm{~min}$, flush of the extraction cell $60 \%$, nitrogen purge $70 \mathrm{~s}$ and the extraction pressure $1500 \mathrm{psi}$. For each extraction, $2 \mathrm{~g}$ of bark powder was loaded into an extraction cell $(34 \mathrm{~mL})$ plugged with a cellulose filter. Each sample was first extracted with hexane and then with ultra high-quality (UHQ) water. The extractive-free bark was consequently lyophilised and stored for carbohydrate analysis. The extractions were performed in duplicates for each sample.

\subsection{Gravimetric Analysis of Total Dissolved Solids (TDS) and Preparation of Stock Solutions}

Bark extracts were analysed gravimetrically to determine their TDS. The extractives collected in hexane were first evaporated to near dryness in a rotary evaporator; the extractives were subsequently transferred to a tared $\left(\mathrm{Kimax}^{\circledR}\right)$ test tube in acetone. Brief sonication of the mixture in an ultrasound bath assisted in the dissolution of lipophilic extractives. The acetone solution was evaporated under nitrogen flow to dryness and the gravimetric amount of total lipophilic extractives determined by weighing the dried extract until a constant mass was achieved. A stock solution of $100 \mathrm{~mL}$ was then prepared by dissolving the extractives in acetone.

The hydrophilic extract in water was first diluted to $100 \mathrm{~mL}$ with UHQ water and stored in a freezer as a stock solution; $10 \mathrm{~mL}$ of the stock solution was then frozen and lyophilised and the gravimetric amount of total hydrophilic extractives determined based on the mass of the lyophilised sample.

\subsection{Analysis of Bark Extractives with Chromatographic Methods}

\subsubsection{Qualitative and Quantitative Analysis by Gas Chromatography (GC)}

The methods used for the qualitative and quantitative analysis of spruce bark extractives groups and individual extractives (both free and esterified) were modified based on the methods reported by Örså and Holmbom (1994) [31].

For the preparation of a sample of bark extracts for qualitative or quantitative analysis, approximately $3 \mathrm{mg}$ of extract was first dried (either under nitrogen flow or by lyophilisation). For quantitative analysis, internal standards were also added and the mixture dried under nitrogen flow. To analyse extractives groups using short-column gas chromatography with a flame ionisation detector (GC-FID), $100 \mu \mathrm{g}$ of four internal standards, namely heneicosanic acid, betulinol, cholesteryl margarate and 1,3-dipalmitoyl-2-oleylglycerol, were added to the sample. For the quantitative analysis of individual compounds, only heneicosanic acid and betulinol were added. Both quantitative and qualitative samples were silylated before analysis by dissolving them in $500 \mu \mathrm{L}$ of pyridine and $300 \mu \mathrm{L}$ of the silylation reagent (BSTFA/TMCS, 99/1, v/v) and by keeping them capped in Kimax ${ }^{\circledR}$ test tubes in an oven at $70{ }^{\circ} \mathrm{C}$ for $1 \mathrm{~h}$.

For the analysis of esterified lipophilic extractives, after the drying of the extract and internal standards, the sample was hydrolysed by adding $1 \mathrm{~mL}$ of $\mathrm{KOH}$ in $90 \% \mathrm{EtOH}$ keeping the mixture in an oven at $70{ }^{\circ} \mathrm{C}$ for $3.5 \mathrm{~h}$. After the hydrolysis, the sample was diluted with $1 \mathrm{~mL}$ of $\mathrm{UHQ}$ water, and the $\mathrm{pH}$ of the mixture was adjusted to 3.5 by the addition of $0.5 \mathrm{M}$ sulphuric acid by using bromocresol green ( 2 drops) as an indicator solution. The hydrolysed compounds were extracted by adding $2 \mathrm{~mL}$ of diethyl ether to the sample mixture, mixing for $1 \mathrm{~min}$, centrifuging the mixture for $5 \mathrm{~min}$ at $2500 \mathrm{rpm}$ and separating the diethyl ether layer by pipetting. The extraction by diethyl ether was repeated two more times and the ether layers were combined. The diethyl ether was then dried under nitrogen flow (and lyophilisation if the sample was too moist), and the silylation of the sample was done as described previously.

The individual compounds were analysed quantitatively using an Agilent 6850 GCFID equipment and qualitatively using an Hewlett Packard 5973 gas chromatograph-mass 
spectrometry (GC-MS) equipment. The GC systems were equipped with an HP-5 column (30 $\mathrm{m} \times 0.32 \mathrm{~mm}$ with $0.25 \mu \mathrm{m}$ film), injecting the sample at $290{ }^{\circ} \mathrm{C}$ and detecting the compounds with a FID/MS detector at $300{ }^{\circ} \mathrm{C}$. In the applied method, the starting temperature was $100{ }^{\circ} \mathrm{C}$, where the sample was kept for $1.5 \mathrm{~min}$, after which the temperature was first raised $\left(6^{\circ} \mathrm{C} / \mathrm{min}\right)$ to $180^{\circ} \mathrm{C}$ and then raised $\left(4^{\circ} \mathrm{C} / \mathrm{min}\right)$ to $290{ }^{\circ} \mathrm{C}$, where it was kept for $13 \mathrm{~min}$. After this, it was finally raised $\left(4^{\circ} \mathrm{C} / \mathrm{min}\right)$ to $300^{\circ} \mathrm{C}$, where it was kept for $20 \mathrm{~min}$.

The extractives compound groups were analysed quantitatively with a short-column GC-FID equipped with an HP1/Simulated Distillation column $(7.5 \mathrm{~m} \times 0.53 \mathrm{~mm}$ with $0.15 \mu \mathrm{m}$ film). The samples were injected on column at $90{ }^{\circ} \mathrm{C}$, and the compounds were detected with FID at $320^{\circ} \mathrm{C}$. In the method used, the starting temperature was $90^{\circ} \mathrm{C}$, from which the temperature raised $\left(12{ }^{\circ} \mathrm{C} / \mathrm{min}\right)$ to $320^{\circ} \mathrm{C}$, and this temperature was kept for $10 \mathrm{~min}$.

2.8.2. Qualitative and Quantitative Analysis by High-Performance Liquid Chromatography (HPLC)

For the qualitative analysis of bark samples with HPLC, $1 \mathrm{mg} / \mathrm{mL}$ dilution of bark water extract was prepared in $\mathrm{MeOH} / \mathrm{H}_{2} \mathrm{O}(50 / 50, v / v)$, and the sample was filtrated through a $0.2 \mu \mathrm{m}$ polytetrafluoroethylene (PTFE) filter. The sample was then analysed with an Agilent 1290 LC (liquid chromatography) instrument equipped with a ZORBAX StableBond column (80A C18, $2.1 \mathrm{~mm} \times 100 \mathrm{~mm}, 1.8 \mu \mathrm{m}, 1200 \mathrm{bar})$, a ZORBAX SBC18 UHPLC guard column $(2.1 \mathrm{~mm}, 1.8 \mu \mathrm{m}), 1290$ Infinity II Diode Array Detector and a 6460 triple quadrupole mass spectrometer (LC/DAD/QQQ). The LC columns were maintained at $30{ }^{\circ} \mathrm{C}$. Two solvents were used for the mobile phase: (A) $0.1 \%$ formic acid in UHQ water and (B) $0.1 \%$ formic acid in acetonitrile. The mobile phase flow rate was $0.3 \mathrm{~mL} / \mathrm{min}$. The run method was modified based on the study by Gabaston et al. [32] and was as follows: $10 \% \mathrm{~B}$ (from 0-1.7 min), 10-20\% B (from 1.7-3.4 min), 20-30\% B (from 3.4-5.1 min), 30\% B (from 8.5-11.9 min), 60-100\% B (from 11.9-15.3 min), 100\% B (from $15.3-17.0 \mathrm{~min}$ ) and 100-10\% B (from 17.0-17.3 $\mathrm{min}$ ). Mass spectrometry analyses were performed in negative mode with a range of $\mathrm{m} / \mathrm{z}$ 100-1200. The drying gas used was nitrogen at $10 \mathrm{~L} / \mathrm{min}$ at $365^{\circ} \mathrm{C}$ with a nebuliser pressure of $40 \mathrm{psi}$. The capillary voltage was 3100 V. Bruker Data Analysis 3.2 software was used for data processing. Trans-piceid was used as an external standard for quantifying the stilbenes and other phenolics separated and identified from the bark water extracts.

\subsection{Carbohydrate Analysis}

The extractives-free bark was analysed for its carbohydrate (cellulose and hemicelluloses) and acid-soluble and acid-insoluble lignin content using acid hydrolysis and acidic methanolysis. The cellulose and lignin contents were determined by acid hydrolysis [33] and the content of the hemicelluloses by acidic methanolysis.

\subsubsection{Acid Hydrolysis}

For acid hydrolysis, approximately $200 \mathrm{mg}$ of the lyophilised extractives-free bark was weighed in a test tube. Each sample was prepared in duplicate. Then $4 \mathrm{~mL}$ of $72 \%$ cold sulphuric acid (stored in a fridge) was added to the sample. The test tube was maintained at $30{ }^{\circ} \mathrm{C}$ in a water bath for $1 \mathrm{~h}$ and was mixed with a glass rod every $5 \mathrm{~min}$. The sample was then carefully transferred to a $250-\mathrm{mL}$ autoclave bottle and was washed with $112 \mathrm{~mL}$ of UHQ water. The samples were then placed into an autoclave (MELAG Autoklav 23) at the pressure of 1 bar $\left(\sim 121^{\circ} \mathrm{C}\right)$ for $1 \mathrm{~h}$. The acid-insoluble lignin was separated from the mixture by filtering the sample with a tared borosilicate glass filter (Munktell MGA 413004) in a vacuum funnel. The amount of insoluble lignin was determined gravimetrically by drying the filter paper together with the solid residue in an oven at $105^{\circ} \mathrm{C}$ to a constant mass. The filtrate was diluted to $500 \mathrm{~mL}$ with UHQ water and was consequently analysed with highperformance anion-exchange chromatography (HPAEC) for its monosaccharide content and with ultraviolet-visible (UV-Vis) spectrometry for its acid-soluble lignin content. 


\subsubsection{High-Performance Anion-Exchange Chromatography (HPAEC) Analysis of Monosaccharides}

The monosaccharides formed during the acid hydrolysis were analysed from the $500 \mathrm{~mL}$ dilution using HPAEC. The standard solutions for HPAEC were prepared using a sulphuric acid concentration corresponding to the samples' background: cold 72\% sulphuric acid ( $3 \mathrm{~mL}$ ) was diluted in $500 \mathrm{~mL}$ with UHQ water. Fucose (500 ppm) was used as the internal standard. Three monosaccharide solutions were made for the preparation of standard solutions: (i) arabinose (400 ppm), galactose (200 ppm) and mannose (200 ppm); (ii) glucose (1000 ppm) and (iii) xylose (1000 ppm). The volumes for the five prepared standard solutions (STD1-STD5), as well as their monosaccharide concentrations, are shown in Table 2.

Table 2. Standard solutions for high-performance anion-exchange chromatography (HPAEC) measurements.

\begin{tabular}{|c|c|c|c|c|c|c|c|c|c|c|}
\hline \multirow{2}{*}{ Mono-Saccharide (Standard) } & \multicolumn{2}{|c|}{ STD1 } & \multicolumn{2}{|c|}{ STD2 } & \multicolumn{2}{|c|}{ STD3 } & \multicolumn{2}{|c|}{ STD4 } & \multicolumn{2}{|c|}{ STD5 } \\
\hline & $\mathbf{V}^{*}$ & $\mathrm{C} * *$ & $\mathbf{V}$ & $\mathrm{C}$ & $\mathbf{V}$ & $\mathrm{C}$ & $\mathbf{V}$ & $\mathrm{C}$ & $\mathbf{V}$ & $\mathrm{C}$ \\
\hline Arabinose & 1 & 4 & 3 & 12 & 6 & 24 & 10 & 40 & 15 & 60 \\
\hline Galactose & 1 & 2 & 3 & 6 & 6 & 12 & 10 & 20 & 15 & 30 \\
\hline Mannose & 1 & 2 & 3 & 6 & 6 & 12 & 10 & 20 & 15 & 30 \\
\hline Glucose & 5 & 50 & 10 & 100 & 15 & 150 & 20 & 200 & 25 & 250 \\
\hline Xylose & 2 & 20 & 4 & 40 & 6 & 60 & 8 & 80 & 10 & 100 \\
\hline
\end{tabular}

*Volume (mL) of used solution in $100 \mathrm{~mL}$ volumetric flask. ** Solution concentration (ppm).

The bark samples (500 mL, UHQ dilution) from acid hydrolysis were analysed with HPAEC (Dionex) using $1 \mathrm{M}$ sodium acetate, $0.5 \mathrm{M}$ sodium acetate $+0.1 \mathrm{M} \mathrm{NaOH}$ and $0.3 \mathrm{M} \mathrm{NaOH}$ solutions as eluents. The analytes were separated in CarboPac PA1 + Guard PA1 columns and were detected using an ED50 detector using carbohydrate pulsing. Postcolumn elute was pumped by an IC25 isocratic pump. Samples for HPAEC analyses were prepared by pipetting $2 \mathrm{~mL}$ of internal standard solution into a $20 \mathrm{~mL}$ volumetric flask and filling the flask with the diluted sample $(500 \mathrm{~mL})$ from acid hydrolysis. This solution (1.0-1.5 mL) was transferred into an HPLC vial by filtrating it through a syringe filter (Phenex RC $0.2 \mu \mathrm{m}$ ).

\subsubsection{Ultraviolet-Visible (UV-Vis) Measurement of Acid-Soluble Lignin}

The amount of acid-soluble lignin was determined from the $500 \mathrm{~mL}$ dilution following acid hydrolysis by UV-Vis spectrometry at $205 \mathrm{~nm}$ according to TAPPI UM 250 standard [34] using an extinction coefficient for softwood of $120 \mathrm{~L} /(\mathrm{gcm})$ [35]. The analysis was done with a Perkin Elmer Lambda 35 UV-Vis spectrometer.

\subsubsection{Acidic Methanolysis}

The amount of hemicelluloses in the spruce bark samples was determined from the extractive-free lyophilised bark by acidic methanolysis modified from the method by Bertaud et al. [36]. An internal standard solution was prepared by dissolving $10 \mathrm{mg}$ of sorbitol into $100 \mathrm{~mL}$ of $\mathrm{MeOH}$. For an external standard solution, $10 \mathrm{mg}$ of pure arabinose, galactose, glucose, xylose, mannose, galacturonic acid and glucuronic acid was dissolved in $100 \mathrm{~mL}$ of UHQ water. Methanolysis reagent was prepared by cooling $100 \mathrm{~mL}$ of $\mathrm{MeOH}$ in an ice bath and carefully adding and mixing $16 \mathrm{~mL}$ of acetyl chloride to the cold $\mathrm{MeOH}$. The reagent was stored at $-20^{\circ} \mathrm{C}$.

For methanolysis, 2-3 mg of the extractive-free bark sample was weighed in a pearshaped flask. For a standard sample, $1 \mathrm{~mL}$ of a standard solution containing all the monosaccharides was added to another pear-shaped flask, and the solvent was evaporated by a rotary evaporator. The methanolysis reagent $(2 \mathrm{~mL})$ was then added to both the sample flasks and standard flasks. The sample flasks were capped with screwed caps, sonicated in an ultrasound bath and kept in an oven at $100{ }^{\circ} \mathrm{C}$ for $3 \mathrm{~h}$. The flasks were cooled before opening them to reduce their pressure. Pyridine $(80 \mu \mathrm{L})$ and $1 \mathrm{~mL}$ of the 
internal standard were added to the samples, and the solvent was evaporated by a rotary evaporator accompanied by a water bath $\left(35-45{ }^{\circ} \mathrm{C}\right)$. Pyridine $(80 \mu \mathrm{L})$ and $250 \mu \mathrm{L}$ of silylation reagent were added to the dried samples. The samples were sonicated in an ultrasound bath and kept in a shaker at room temperature for $40 \mathrm{~min}$. The samples were then filtrated with glass wool and placed in vials for GC analysis.

The samples were analysed with an Agilent gas chromatograph using an HP-5 column ( $30 \mathrm{~m} \times 0.32 \mathrm{~mm}$ with $0.25 \mu \mathrm{m}$ film), injecting at $260{ }^{\circ} \mathrm{C}$ and detecting with a FID at $290{ }^{\circ} \mathrm{C}$. The method used was as follows. The starting temperature was $100^{\circ} \mathrm{C}$, where the sample was kept for $2 \mathrm{~min}$. The temperature was raised $\left(4^{\circ} \mathrm{C} / \mathrm{min}\right)$ to $220^{\circ} \mathrm{C}$, where it was maintained for $2 \mathrm{~min}$ and was finally raised $\left(15^{\circ} \mathrm{C} / \mathrm{min}\right)$ to $300^{\circ} \mathrm{C}$ and kept there for $2 \mathrm{~min}$.

\subsection{Total Phenolic Content (TPC)}

The bark samples' total phenolic content (TPC) was evaluated from the hot-water extracts of bark with the Folin-Ciocalteu method. The Folin-Ciocalteu method was used as described by Singleton and Rossi [37]. Hot-water extracts of bark were diluted, and $0.5 \mathrm{~mL}$ of the solutions was pipetted into a Kimax ${ }^{\circledR}$ test tube. The $0.2 \mathrm{~N}$ Folin-Ciocalteu reagent $(2.5 \mathrm{~mL})$ and $2.0 \mathrm{~mL}$ of sodium carbonate solution $(75 \mathrm{~g} / \mathrm{L})$ were added. The samples were vortexed and placed in a hot-water bath at $50{ }^{\circ} \mathrm{C}$ for $5 \mathrm{~min}$. After cooling $(10 \mathrm{~min})$, the absorbance was measured at $760 \mathrm{~nm}$ with Perkin Elmer Lambda $35 \mathrm{UV}-$ Vis spectrometer.

\subsection{Statistical Analysis of Bark Extractives}

To analyse the statistical differences in the bark's chemical constituents between storage times (i.e., storage time in weeks since the onset of the storage experiment) and seasons (winter vs. summer), a two-way analysis of variance (ANOVA) was used with the assumptions of the normal distribution (assessed by histograms) and the homogeneity of variance. The dependent variables for the analyses were the quantitative amounts of the different extractives groups analysed by GC-FID/HPLC and spectrophotometric methods (UV-Vis). Because of the limited data set of only eight observations per response variable, the assumptions of normality and variance homogeneity were initially not met. To solve the problem, data transformations that maximised normality and minimised variance between sample groups were utilised.

The utilised transformations for the extractives groups were as follows. Logarithmic transformation (Ln) was used to normalise the distribution of all extractives groups except for triglycerides, alcohols, sugars and unidentified hydrophilic extractives. With triglycerides and unidentified hydrophilic extractives, cosine transformation was used to normalise the distribution, whereas sine transformation was used for alcohols, and the absolute value of cosine transformation was used for sugars.

\section{Results and Discussion}

\subsection{Overall Change in Chemical Composition}

In summary of the results, the overall change in the chemical composition of winterand summer-stored bark is presented in Figure 3. According to the results, the proportion of extractives in bark gradually decreased while the extractive-free fraction increased. The hot-water extract was the most substantial fraction at the beginning of the storage period, both during winter and summer. In contrast, at the end of the storage period, hemicelluloses and lignin comprised the largest fractions during winter and summer, respectively. It should be noted that since no new hemicellulose or lignin is expected to be formed during storage, their observed increase was relative to the loss of extractives. The amount of cellulose and lignin was not determined for samples of weeks 4 and 12, and thus, were included in the group of unidentified compounds of bark. By comparing the zero-samples to 24-week samples, it seems that, in general, the relative proportion of unidentified compounds increases slightly during storage. 


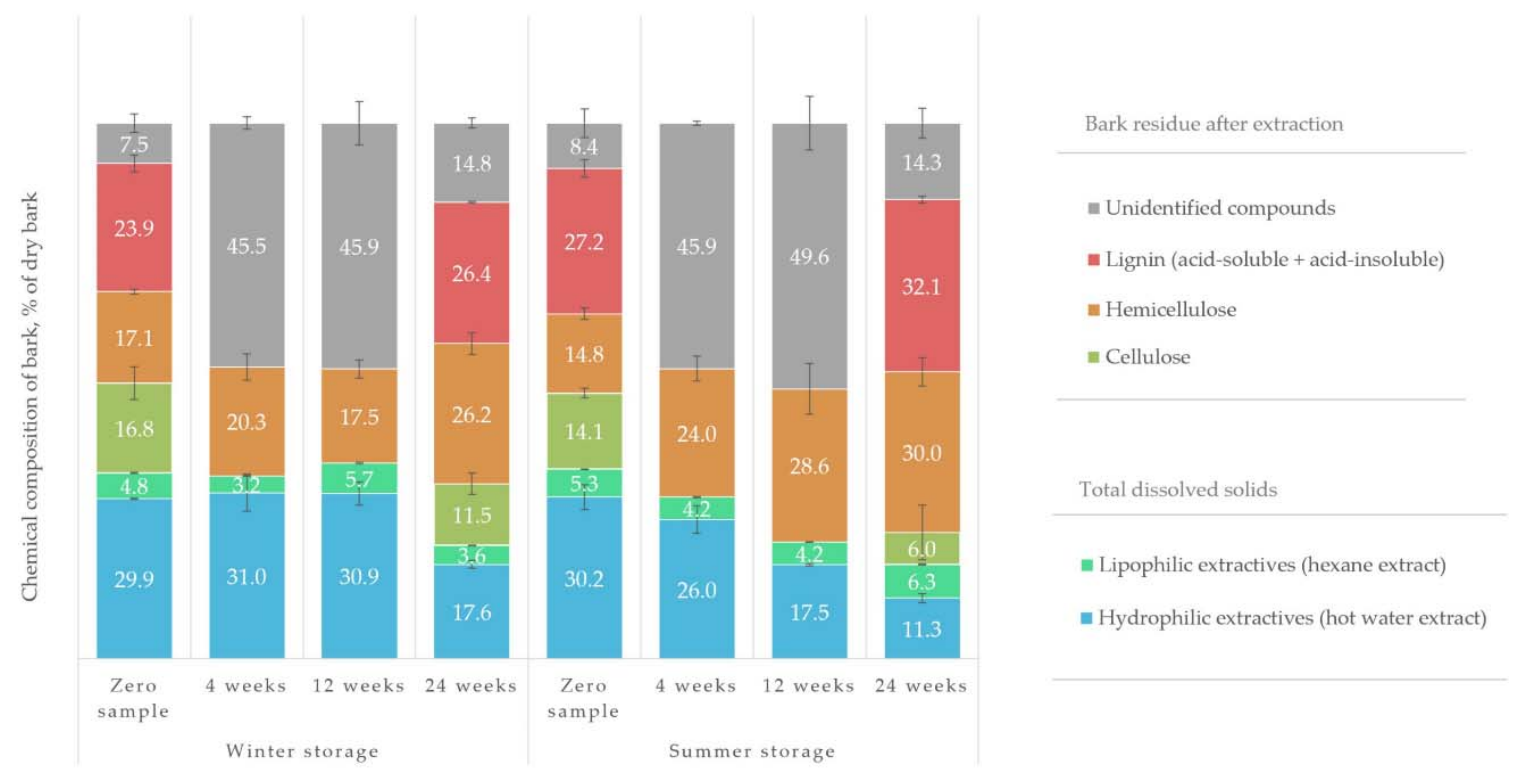

Figure 3. Summary of the overall chemical change in bark samples during the winter and summer storage. Total dissolved solids (both hydrophilic and lipophilic), carbohydrate content (cellulose and hemicelluloses), the amount of lignin and unidentified compounds are shown. The amount of cellulose and lignin was not determined for samples of weeks 4 and 12 .

\subsection{Total Dissolved Solids (TDS)}

The TDS of the hexane and water extracts of spruce bark from both the winter and summer saw log storage experiments are shown in Figure 3. The TDS of the water extracts were much higher than those of the hexane extracts, indicating that hydrophilic extractives were more abundant in spruce bark in comparison to the lipophilic extractives.

\subsubsection{TDS of Hydrophilic Extractives}

The initial TDS of hydrophilic extractives in the bark zero-samples during both the winter and summer experimental setups were about equal. Overall, the hydrophilic extractives degraded much faster than the lipophilic extractives. However, the degradation rate in the hydrophilic extractives was more pronounced during the summer, when the samples were exposed to higher temperatures, higher levels of UV light and the increased activity of insects, bacteria and fungi. The TDS of hydrophilic extractives decrease consistently during summer storage, but during winter, the total amount of hydrophilic extractives remained unaffected up to 12 weeks of storage. The TDS of the saw log bark at 12 weeks of winter storage was notably high in both the water and the hexane extracts. This result should be interpreted in light of the fact that all bark for any given sample came from just two separate logs.

The natural variation in extractives content between any two trees is affected by several factors, the impact of which is not always clear. Such factors include the age of the tree, weather conditions, soil nutrients, pollution and the level of exposure to UV radiation. In the case of the bark sample at 12 weeks of winter storage, both logs contributing to the sample happened to be from trees over 30 years younger than the average age of the sample trees. The exact age of the sample trees could not be taken into account during the construction phase of the experimental setups since the ages were determined later at the laboratory. The trees were instead chosen based on a similar outward appearance (height and diameter), yet a significant difference was observed in the trees' age. This result indicated that the trees have grown at markedly different speeds, probably affected by different sunlight exposure, which in turn affected the extractives fractions. It should be noted that some disparity between trees is always expected regardless of the criteria used to choose the raw material. 
This study's scope is limited because of the relatively small sample size (bark from only two logs per sample). Thus, it cannot provide a reliable relationship between all the sample variables (such as tree age and TDS). Such an inquiry would require tens of biological replicates per sampling, which was excessive for this study. This study's scope was rather to provide a directive overview of the chemical degradation occurring in the spruce bark extractives during winter and summer storage, which would benefit industrial parties interested in the valorisation of woody biomass. Also outside of the scope of this study was the detailed study of the extractives' differences in the bark from different heights of individual logs. It is well known that the concentration of extractives in bark decreases as one moves from stump to crown. However, industrial biorefining of bark would necessarily be holistic and not targeted at bark from only a specific area of the log. Thus, a mean value for the saw log bark extractives content was aimed at by combining the bark from the three sample discs cut from the logs (according to Figure 1b) and by combining the bark of the two individual saw logs of each sampling.

\subsubsection{TDS of Lipophilic Extractives}

The total amount of lipophilic extractives in the bark remained relatively stable throughout the storage period of 24 weeks, both during winter and summer. However, this result does not mean that the lipophilic extractives remained chemically unaltered during the storage period. The variation in the amount of TDS of lipophilic extractives was $3.2-5.7 \%$ of dry matter during winter storage and $4.2-6.3 \%$ dry matter during summer storage, indicating that lipophilic extractives were more abundant in bark during the summer. Similar TDS levels (4.0-5.0\%) for lipophilic extractives from spruce bark have been reported previously [38] utilising the Soxhlet extraction method.

\subsection{Qualitative and Quantitative Analysis of Bark Extracts}

\subsubsection{Qualitative Analysis by Gas Chromatography-Mass Spectrometry (GC-MS)}

The most prominent lipophilic and hydrophilic extractives identified by GC-MS from the spruce bark hexane and water extracts are listed in Tables 3 and 4, respectively. The extractives are listed according to their significance among all the analysed samples. The main categories of lipophilic extractives were resin and fatty acids, diterpenoids, sterols and fatty alcohols (i.e., waxes). The main categories of hydrophilic extractives were sugars, organic acids, stilbenes, alcohols and flavonoids. The category defined in the table as others comprised the extractives, which (although visible in the GC chromatograms) could not be identified. Identifying these compounds was impossible either because their amount was too low, the peaks overlapped, a lack of a meaningful library match or the MS method's solvent delay caused the peaks to be undetected. The reference chromatograms from the long-column GC-MS/FID analysis of the hexane extracts of both free and esterified extractives are given in Appendix $\mathrm{A}$ and Figures $\mathrm{A} 1$ and $\mathrm{A} 2$, respectively, while the chromatogram of the short-column GC-FID for the hexane extract is shown in Figure A3. The long- and short-column reference chromatograms for the water extract's hydrophilic compounds can be seen in Figures A4 and A5, respectively. The compounds listed in Tables 3 and 4 are linked to the chromatogram peaks with specific symbols to help with their interpretation.

As can be seen from Table 3, resin and fatty acids together accounted for more than half of the identified lipophilic compounds, with diterpenoids, sterols and fatty alcohols being the minor compounds. The most important resin acids found from the spruce bark samples were dehydroabietic, isopimaric, abietic, levopimaric, neoabietic and palustric acids, representing $77 \%$ of the total amount of resin acids. The most prominent fatty acids were $18: 1,18: 2,18: 3,22: 0,16: 0,20: 0$ and $24: 0$, representing $88 \%$ of the total amount of fatty acids. It should be noted that many triglycerides and steryl esters had fatty acids bound to them, which were released upon hydrolysis with $\mathrm{KOH}$ (see Section 2.8.1). 
Table 3. Primary spruce bark lipophilic extractives identified and quantified by gas chromatography-mass spectrometry (GC-MS).

\begin{tabular}{|c|c|c|c|c|}
\hline \multicolumn{2}{|c|}{ Lipophilic Extractives Groups } & \multicolumn{3}{|c|}{ Amount, \% of Total Lipophilic Extractives } \\
\hline \multicolumn{2}{|r|}{ Resin acids } & \multicolumn{3}{|c|}{44} \\
\hline \multicolumn{2}{|r|}{ Fatty acids } & \multicolumn{3}{|c|}{21} \\
\hline \multicolumn{2}{|r|}{ Diterpenoids } & \multicolumn{3}{|c|}{14} \\
\hline \multicolumn{2}{|r|}{ Other } & \multicolumn{3}{|c|}{10} \\
\hline \multirow{2}{*}{\multicolumn{2}{|c|}{$\begin{array}{c}\text { Sterols } \\
\text { Fatty alcohols }\end{array}$}} & \multicolumn{3}{|c|}{8} \\
\hline & & & 3 & \\
\hline \multirow[t]{16}{*}{ Resin acids } & Compound & Amount, $\%$ of total resin acids & Retention time, min & Symbol \\
\hline & Dehydroabietic acid & 23 & 30.91 & $\mathrm{a}$ \\
\hline & Isopimaric acid & 16 & 29.91 & $\mathrm{~b}$ \\
\hline & Abietic acid & 10 & 31.44 & $\mathrm{c}$ \\
\hline & Levopimaric acid & 10 & 30.73 & $\mathrm{~d}$ \\
\hline & Neoabietic acid & 9 & 33.19 & $\mathrm{e}$ \\
\hline & Palustirc acid & 9 & 30.32 & $\mathrm{f}$ \\
\hline & Hydroxydehydroabietic acid 1 & 3 & 34.60 & $\mathrm{~g}$ \\
\hline & Sandaracopimaric acid & 3 & 29.62 & $\mathrm{~h}$ \\
\hline & Hydroxydehydroabietic acid 2 & 3 & 34.01 & $\mathrm{i}$ \\
\hline & 4-Hydroxycinnamic acid & 2 & 21.89 & $\mathrm{j}$ \\
\hline & Imbricatolic acid & 2 & 33.00 & $\mathrm{k}$ \\
\hline & Pimaric acid & 2 & 29.30 & 1 \\
\hline & Unidentified hydroxy resin acid & 2 & 35.53 & $\mathrm{~m}$ \\
\hline & Ferulic acid & 1 & 25.04 & $\mathrm{n}$ \\
\hline & 2,4-Dihydroxybutanoic acid & 1 & 11.23 & o \\
\hline \multirow[t]{13}{*}{ Fatty acids } & Compound & Amount, $\%$ of total fatty acids & Retention time, min & Symbol \\
\hline & Acid 18:1 & 24 & 27.43 & $\mathrm{p}$ \\
\hline & Acid 18:2 & 23 & 27.32 & $\mathrm{q}$ \\
\hline & Acid 18:3 & 16 & 26.93 & $\mathrm{r}$ \\
\hline & Acid 22:0 & 9 & 35.31 & $\mathrm{~s}$ \\
\hline & Acid 16:0 & 6 & 23.93 & $\mathrm{t}$ \\
\hline & Acid 20:0 & 5 & 31.70 & $\mathrm{u}$ \\
\hline & Acid 24:0 & 5 & 38.71 & $\mathrm{v}$ \\
\hline & Acid 18:0 & 4 & 27.89 & w \\
\hline & Acid 17:0 & 3 & 25.37 & $x$ \\
\hline & Acid 25:0 & 2 & 35.10 & $\mathrm{y}$ \\
\hline & Acid 15:0 & 1 & 7.66 & $\mathrm{z}$ \\
\hline & Docosanedioic acid & 0.5 & 42.55 & A \\
\hline \multirow[t]{13}{*}{ Diterpenoids } & Compound & Amount, $\%$ of total diterpenoids & Retention time, $\min$ & Symbol \\
\hline & $\Delta^{13}$-(trans-)neoabienol & 26 & 26.34 & B \\
\hline & Manool & 18 & 25.95 & $\mathrm{C}$ \\
\hline & Thunbergol & 17 & 25.76 & $\mathrm{D}$ \\
\hline & cis-Abienol & 9 & 26.94 & $\mathrm{E}$ \\
\hline & Palustral & 5 & 28.01 & $\mathrm{~F}$ \\
\hline & Dehydroabietal & 4 & 28.63 & G \\
\hline & Cubebene & 4 & 8.67 & $\mathrm{H}$ \\
\hline & Isopimarol & 3 & 28.18 & I \\
\hline & Epimanoyl oxide & 3 & 23.61 & $\mathrm{~J}$ \\
\hline & Pimarol & 3 & 31.00 & $\mathrm{~K}$ \\
\hline & Isopimaral & 2 & 27.46 & $\mathrm{~L}$ \\
\hline & Cadinene & 1 & 9.21 & $\mathrm{M}$ \\
\hline \multirow[t]{6}{*}{ Sterols } & Compound & Amount, $\%$ of total sterols & Retention time, min & Symbol \\
\hline & Sitosterol & 74 & 48.02 & $\mathrm{~N}$ \\
\hline & Campesterol & 16 & 46.05 & $\mathrm{O}$ \\
\hline & Diglycerol & 6 & 10.54 & $\mathrm{P}$ \\
\hline & 24-Methylenecycloartanone & 3 & 55.75 & Q \\
\hline & Acid 18:2 monoglyceride & 1 & 10.22 & $\mathrm{R}$ \\
\hline \multirow[t]{5}{*}{ Fatty alcohols } & Compound & Amount, $\%$ of total fatty alcohols & Retention time, min & Symbol \\
\hline & Alcohol 22:0 & 37 & 33.72 & S \\
\hline & Alcohol 24:0 & 28 & 37.18 & $\mathrm{~T}$ \\
\hline & Alcohol 18:0 & 17 & 26.16 & $\mathrm{U}$ \\
\hline & Alcohol 15:0 & 17 & 32.51 & $\mathrm{~V}$ \\
\hline
\end{tabular}


Table 4. The primary spruce bark hydrophilic extractives identified via gas chromatography-mass spectrometry (GC-MS).

\begin{tabular}{|c|c|c|c|c|}
\hline \multicolumn{2}{|c|}{ Hydrophilic Extractives Groups } & \multicolumn{3}{|c|}{ Amount, \% of Total Hydrophilic Extractives } \\
\hline \multicolumn{2}{|r|}{ Sugars } & \multicolumn{3}{|c|}{37} \\
\hline \multicolumn{2}{|r|}{ Organic acids } & \multicolumn{3}{|c|}{25} \\
\hline \multicolumn{2}{|r|}{ Others } & \multicolumn{3}{|c|}{12} \\
\hline \multicolumn{2}{|r|}{ Stilbenes } & \multicolumn{3}{|c|}{11} \\
\hline \multicolumn{2}{|r|}{ Alcohols } & \multicolumn{3}{|c|}{10} \\
\hline \multicolumn{2}{|r|}{ Flavonoids } & \multicolumn{3}{|c|}{4} \\
\hline \multirow[t]{9}{*}{ Sugars } & Compound & Amount, $\%$ of total sugars & Retention time, $\min$ & Symbol \\
\hline & Glucose & 59 & $\begin{array}{c}19.31,19.95,21.45,21.66 \\
23.30\end{array}$ & $a, b, c, d, e$ \\
\hline & Sucrose & 20 & $36.44,45.43,52.05$ & $\mathrm{f}, \mathrm{g}, \mathrm{h}$ \\
\hline & Maltose & 9 & $34.64,38.06,38.61,40.46$ & $i, j, k, 1$ \\
\hline & Galactose & 2 & $15.76,21.94,44.69$ & $\mathrm{~m}, \mathrm{n}, \mathrm{o}$ \\
\hline & Cellobiose & 1 & $44.94,47.65,50.76$ & $\mathrm{p}, \mathrm{q}, \mathrm{r}$ \\
\hline & Trehalose & 1 & 37.45 & $\mathrm{~s}$ \\
\hline & Lactulose & 1 & 44.50 & $\mathrm{t}$ \\
\hline & $\alpha$-Lactose & 1 & 44.30 & $\mathrm{u}$ \\
\hline \multirow[t]{8}{*}{ Organic acids } & Compound & Amount, $\%$ of total organic acids & Retention time, min & Symbol \\
\hline & Gluconic acid & 47 & $19.66,23.77$ & $\mathrm{~V}, \mathrm{w}$ \\
\hline & Aconitic acid & 24 & 19.82 & $\mathrm{x}$ \\
\hline & Quinic acid & 20 & 20.80 & $\mathrm{y}$ \\
\hline & Malic acid & 4 & 13.20 & $\mathrm{Z}$ \\
\hline & Shikimic acid & 2 & 19.45 & A \\
\hline & Docosanedioic acid & 1 & 42.55 & $\mathrm{~B}$ \\
\hline & 3,4-Dihydroxymandelic acid & 1 & 41.14 & $\mathrm{C}$ \\
\hline \multirow[t]{6}{*}{ Stilbenes } & Compound & Amount, \% of total stilbenes & Retention time, min & Symbol \\
\hline & Isorhapontin & 54 & 66.45 & $\mathrm{D}, \mathrm{E}$ \\
\hline & Astringin & 18 & 65.80 & $\mathrm{~F}$ \\
\hline & Piceid & 17 & 61.25 & G \\
\hline & cis-Piceatannol & 6 & 39.56 & $\mathrm{H}$ \\
\hline & Rhapontigenin & 5 & 39.35 & I \\
\hline \multirow[t]{10}{*}{ Alcohols } & Compound & Amount, \% of total alcohols & Retention time, min & Symbol \\
\hline & Pinitol & 31 & 19.94 & $\mathrm{~J}$ \\
\hline & Salicin & 14 & 41.87 & $\mathrm{~K}$ \\
\hline & Guaiacyl glycerol & 13 & $16.42,40.33$ & $\mathrm{~L}, \mathrm{M}$ \\
\hline & Maltotriitol & 11 & $39.00,43.34$ & $\mathrm{~N}, \mathrm{O}$ \\
\hline & Maltitol & 10 & 44.00 & $\mathrm{P}$ \\
\hline & Inositol & 6 & 25.40 & Q \\
\hline & Arabitol & 6 & 17.87 & $\mathrm{R}$ \\
\hline & Mannitol & 5 & 22.26 & $S$ \\
\hline & Dihydroconiferin & 4 & 40.78 & $\mathrm{~T}$ \\
\hline \multirow[t]{6}{*}{ Flavonoids } & Compound & Amount, \% of total flavonoids & Retention time, min & Symbol \\
\hline & Taxifolin glycoside & 26 & 42.39 & $\mathrm{U}$ \\
\hline & Taxifolin & 21 & 41.51 & $\mathrm{~V}$ \\
\hline & Catechin & 21 & 40.07 & W \\
\hline & Naringin & 20 & $45.79,48.80$ & $X, Y$ \\
\hline & Ampelopsin & 12 & 42.17 & Z \\
\hline
\end{tabular}

Detailed qualification of the lipophilic compounds visible only in the short-column spectrum, that is, steryl esters and triglycerides, was limited because this measurement was done on equipment without a mass detector and only with FID. The general group identification of triglycerides and steryl esters, as seen in Figure A3, was, however, possible due to previous studies that used the same method for the group analysis of wood extractives [31,39].

The results in Table 4 demonstrate that the most significant part (37\%) of the hydrophilic water extract in all the samples was accounted for by various soluble sugars, followed by organic acids (25\%). Stilbenes and alcohols made up $11 \%$ and $10 \%$ of the identified extractives, respectively, while the amount of flavonoids present was only $4 \%$. Even with short-column GC, a relatively large part of the water extract was left uniden- 
tified. The unidentified hydrophilic compounds contained such large oligomeric and polymeric molecules that they could not be analysed in the gas phase even after silylation. Such compounds would presumably have contained procyanidins, oligomeric phenolic compounds (e.g., stilbenes) and sugars as well as lignin. Based on a recent study's analytical pyrolysis results, there also appeared to be lignin fragments present in hot-water extracts of spruce [40]. However, as shown in Figure A5, the short-column GC did reveal two additional compound groups, which, based on a previous study [41], could be identified as dilignans and sesquilignans. However, the lack of monomeric lignans in the studied bark samples, combined with the fact that HPLC analysis of water extracts confirmed the presence of distilbenes, suggested that these compounds should more likely be counted as distilbenes and sesquistilbenes. Nevertheless, the lack of a mass detector in the short-column GC prevented the final confirmation of this presumption.

\subsubsection{Quantitative Analysis by Gas Chromatography with a Flame Ionisation} Detector (GC-FID)

The changes in the amount of lipophilic extractives in the bark samples during winter and summer storage are shown in Figure 4. The average amount of identified lipophilic extractives during winter and summer was around $43 \mathrm{mg} / \mathrm{g}$ and $50 \mathrm{mg} / \mathrm{g}$ of dry matter. In comparison, approximately $20 \mathrm{mg} / \mathrm{g}$ and $23 \mathrm{mg} / \mathrm{g}$ of dry matter were left unidentified using chromatographic methods during winter and summer, respectively. Based on the total amount of extractives, no clear trends in the extractives decay could be observed. Instead, the changes that were seen could be understood to reflect the natural variation in the amount of lipophilic compounds between any saw logs of similar outward appearance.

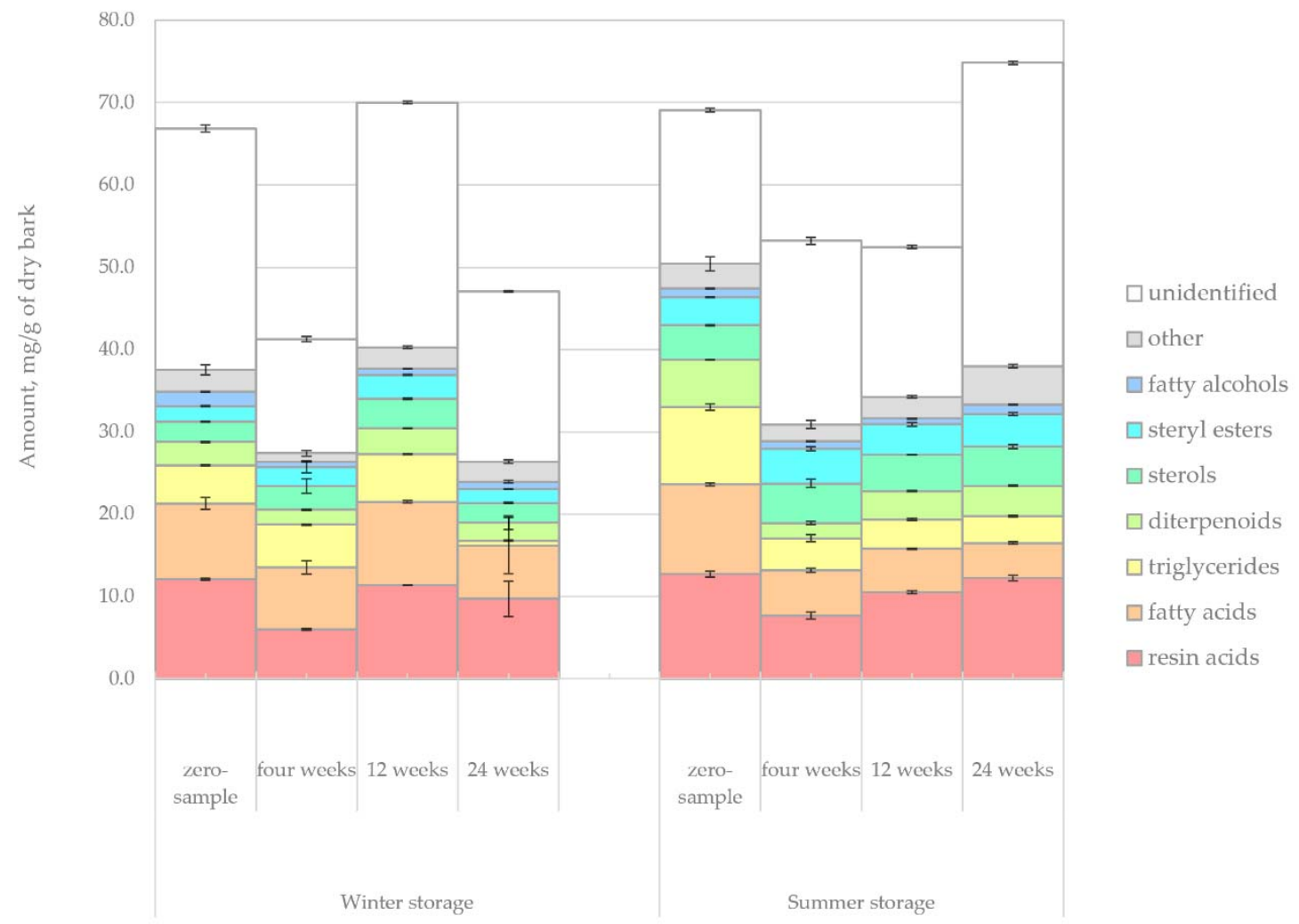

Figure 4. Changes in the amount of lipophilic compounds (mg/g of dry matter) in saw log bark during summer and winter storage periods. Results presented here are a combination of the quantified long-column gas chromatography with a flame ionisation detector (GC-FID) individual free and esterified compounds and the short-column GC-FID extractives groups (triglycerides and steryl esters). 
A more in-depth view of the different compound groups revealed clear trends, such as the gradual decrease of triglycerides because of hydrolysis, a well-known reaction during wood storage $[9,15,42]$. While the summer-stored bark lost triglycerides faster at the beginning of the storage period, from week 12 onwards (as the temperatures decreased from $15{ }^{\circ} \mathrm{C}$ to $0{ }^{\circ} \mathrm{C}$ ), hydrolysis reactions were also reduced. In the winter-stored bark, triglycerides' hydrolysis was limited for the first 12 weeks of storage, after which, as the temperatures rose to $20^{\circ} \mathrm{C}$, the triglycerides were lost rapidly. A similar pattern of degradation could be seen in the total amount of fatty acids. In the summer-stored bark, compared to the winter-stored bark, there was a $44 \%$ increase of diterpenoids, $19 \%$ increase of resin acids, $4 \%$ increase of sterols, $51 \%$ increase of other lipophilic compounds, $73 \%$ increase of steryl esters and $24 \%$ increase of triglycerides during storage. The higher lipophilic content during the summer storage agreed with a previous study [43], where it was shown that higher temperatures increased the hydrolysis of esterified compounds.

The changes in the amount of hydrophilic compounds during the winter and summer storage periods are shown in Figure 5. Unlike in the case of lipophilic compounds, clear trends were observed for hydrophilic extractives. The total amount of extractives decreased $41 \%$ during winter storage and $62 \%$ during summer storage. This difference could easily be understood due to the seasonal effects, namely, elevated microbial activity, increased rate of hydrolysis and increased UV radiation during the warm summer months. During summer, the decrease of extractives was immediately noted after 4 weeks of storage, but the extractives content remained high for 12 weeks during winter storage.

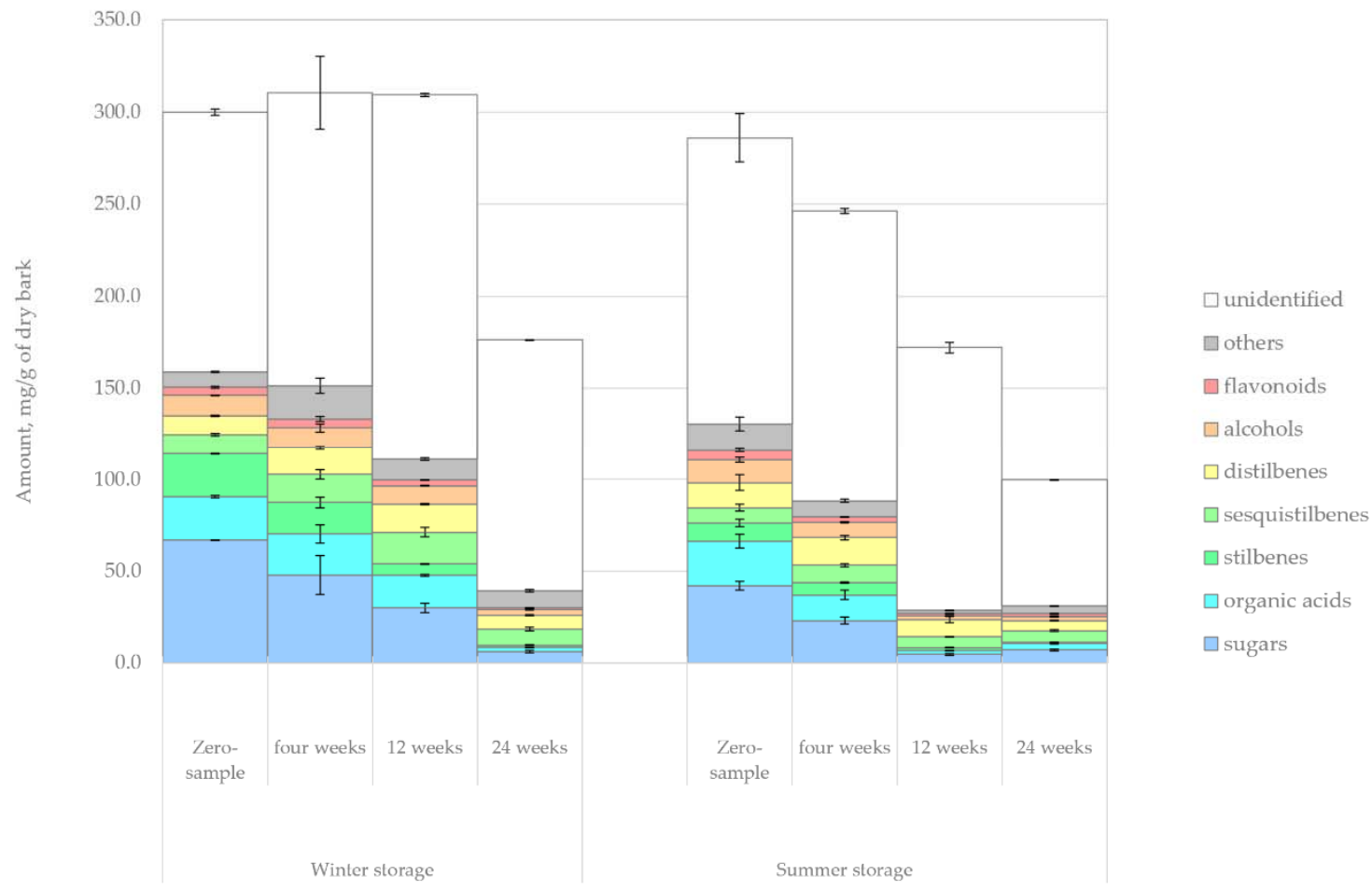

Figure 5. Changes in the amount of hydrophilic compounds ( $\mathrm{mg} / \mathrm{g}$ of dry matter) in saw log bark during summer and winter storage periods. The identification of the extractives group sesquistilbenes is conjectural. It is also possible that this group should be identified as sesquilignans.

It should be noted that the degradation rate of hydrophilic extractives reported here is not as significant as in previous studies that focus on the storage of chipped wood, bark or logging residue in large piles. Ekman, as cited by Sjöström [42], has reported even 50\% degradation of hydrophilic extractives in 50 days. A faster loss of hydrophilic compounds in pile-stored material, compared to the storage of saw logs, could be expected because, 
in pile storage, various factors increase the likelihood of material losses, such as smaller particle size, pile compactness and self-heating caused by microbial activity $[10,11,44]$.

A more in-depth look at the individual compounds' changes during storage based on extractives groups is given in Figures 6-10 for lipophilic extractives and in Figures 11-15 for hydrophilic extractives. The exact amounts of the different compounds presented at each figure as well as their standard deviations are presented as Supplementary Files (link to Supplementary Files can be found at the end of the article).

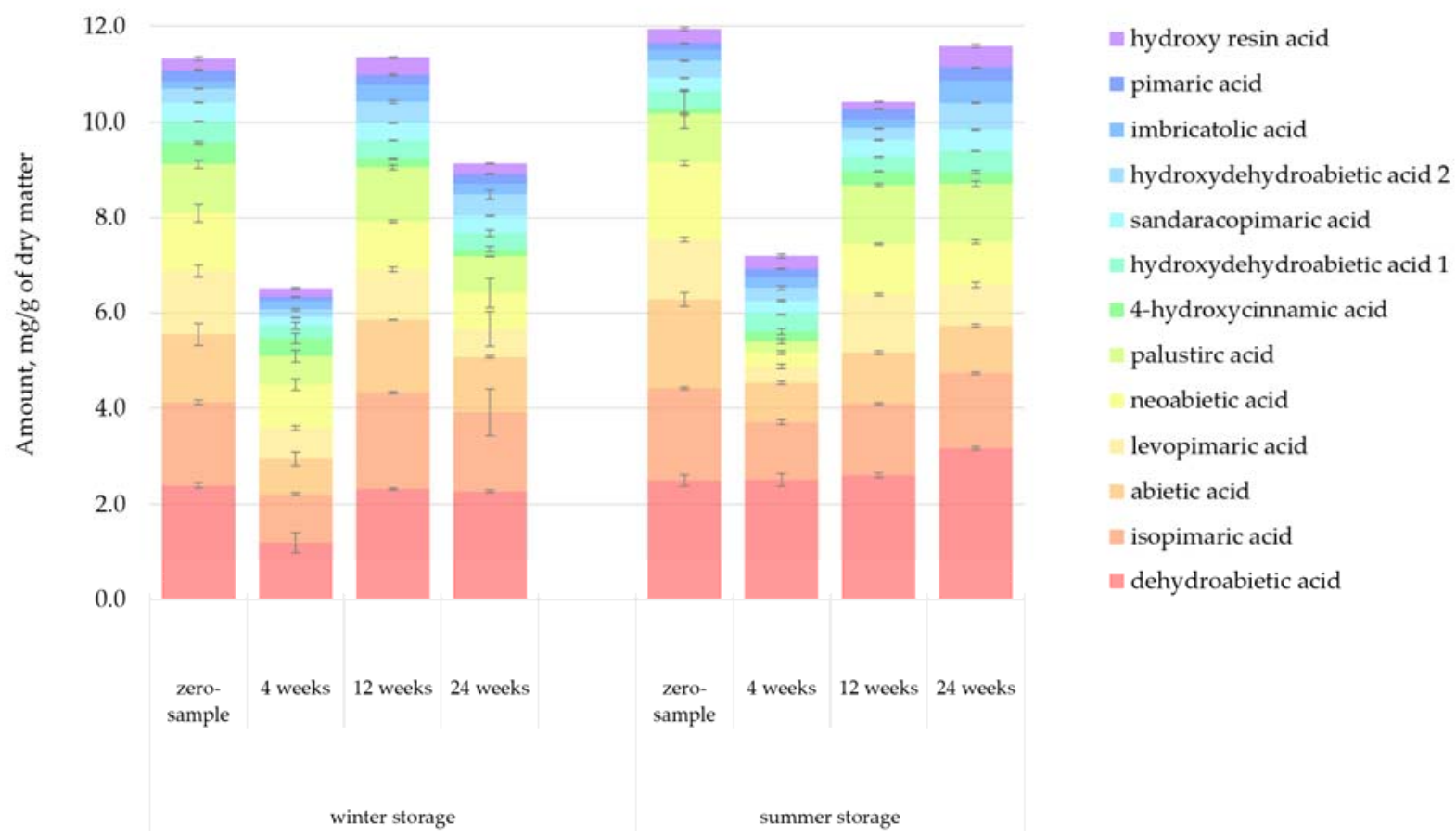

Figure 6. Changes in resin acids during summer and winter storage periods of saw log bark.

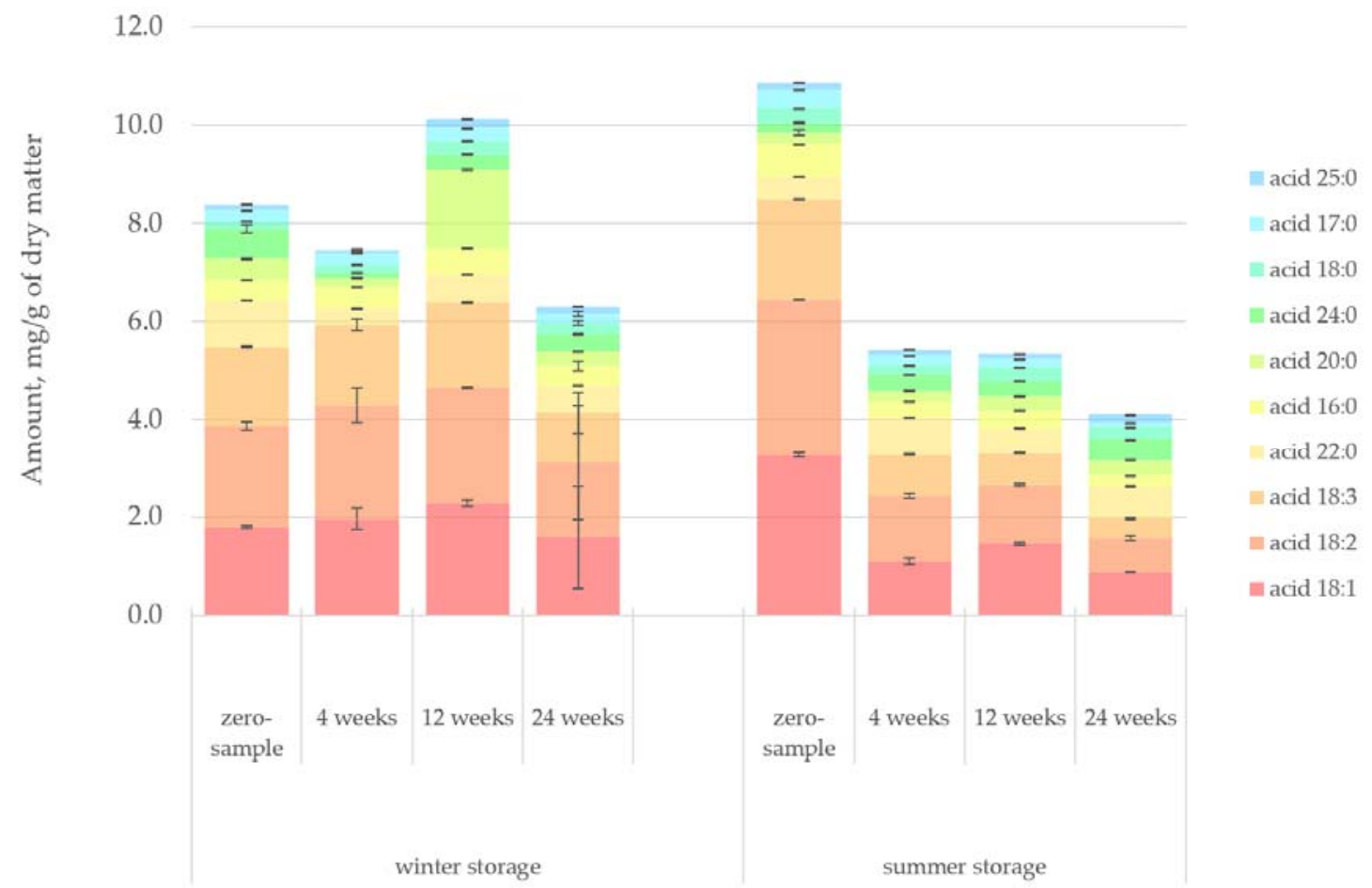

Figure 7. Changes in fatty acids during summer and winter storage periods of saw log bark. 


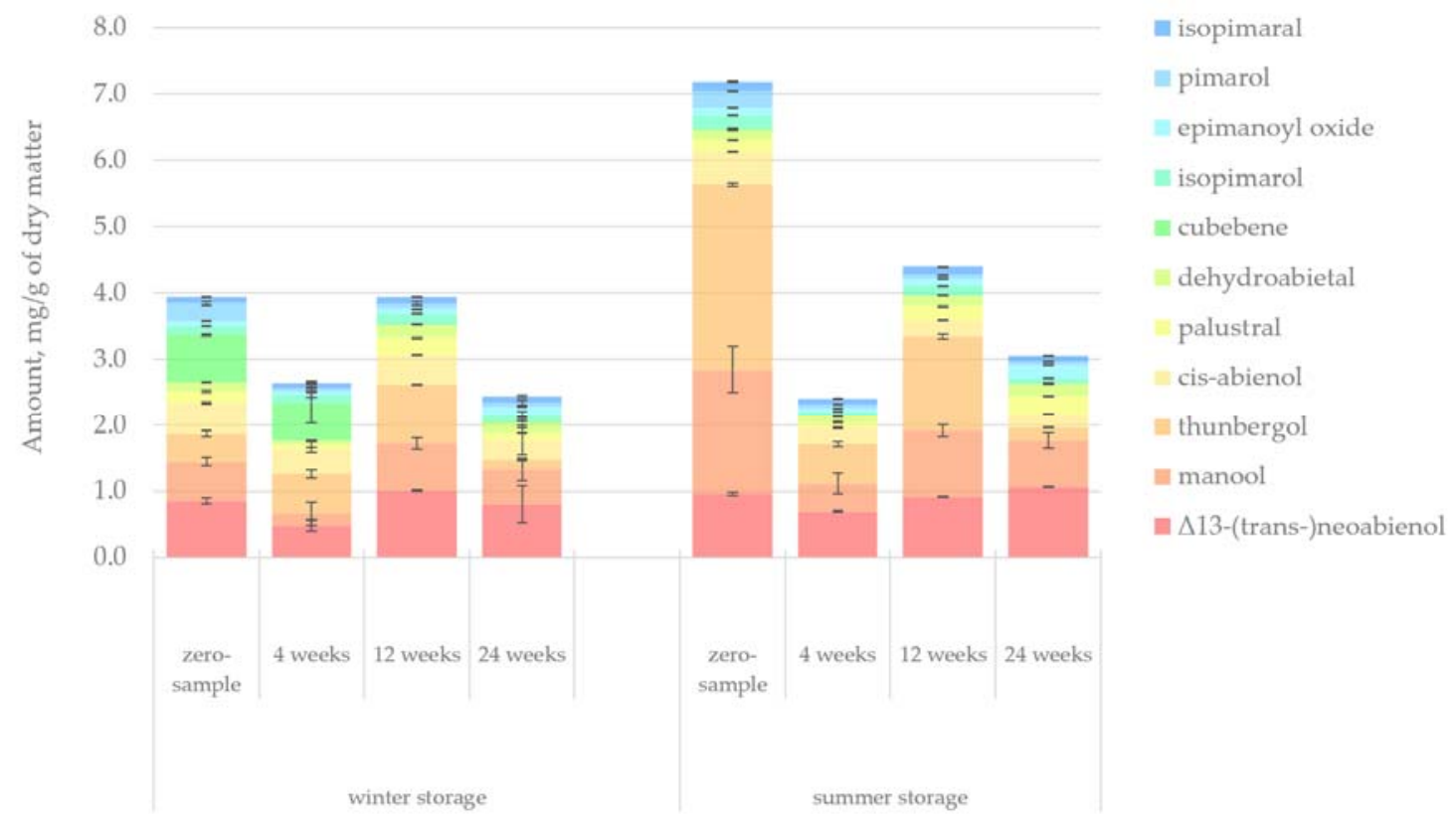

Figure 8. The changes in diterpenoids during summer and winter storage periods of saw log bark.

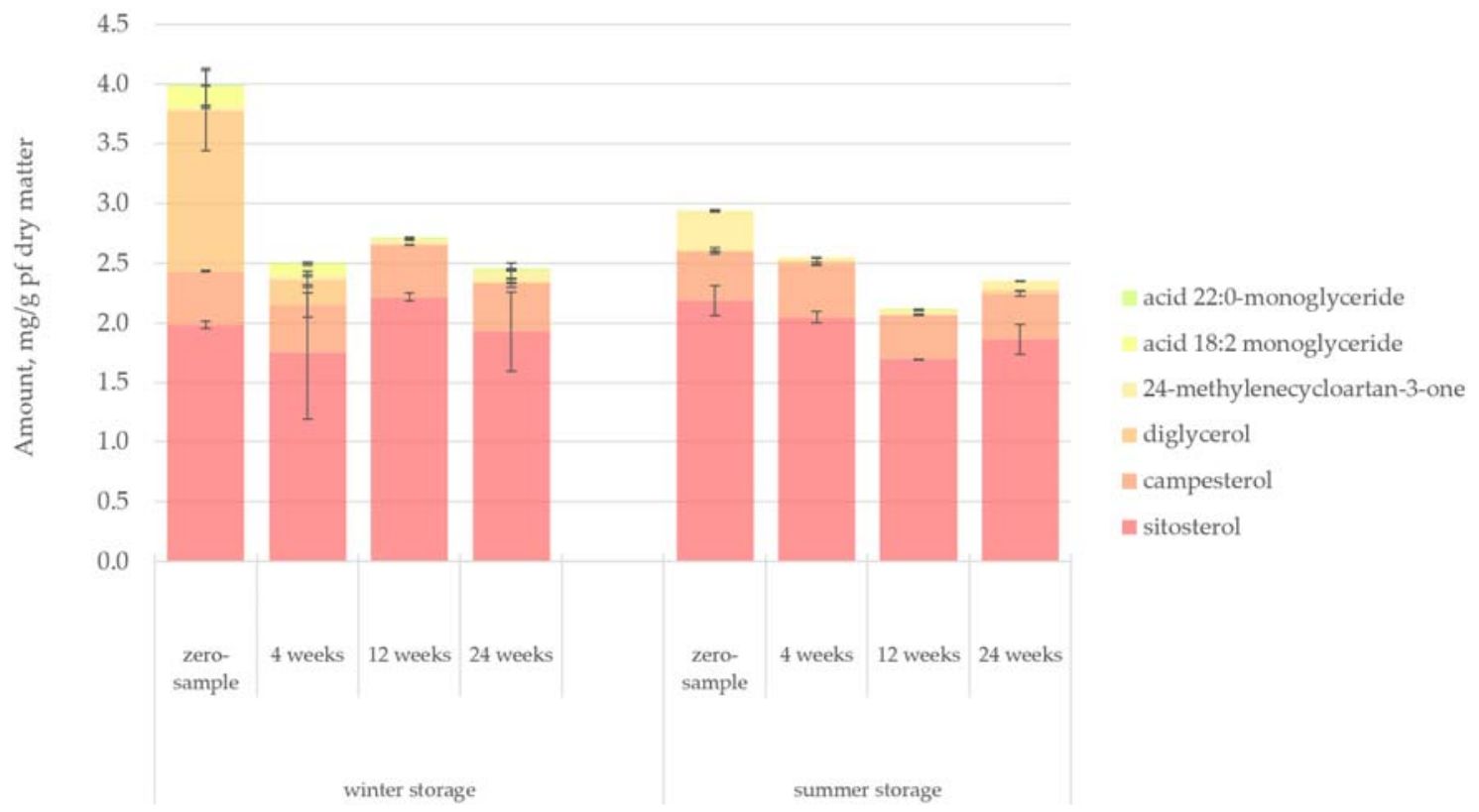

Figure 9. Changes in sterols during summer and winter storage periods of saw log bark.

Figure 6 presents the quantified amount of resin acids in the lipophilic bark extracts. There appeared to be a general correlation between the total amount of resin acids and the total amount of lipophilic extractives. The total amount of resin acids remained relatively constant throughout the storage periods. Previous studies have demonstrated that resin acids can be resistant to microbial degradation [16]. Samples from week 4 had a notably lower amount of resin acids compared to other samples. However, this result should be interpreted as a sign of the natural variance in the amount of lipophilic compounds between trees, not as a general principle. 


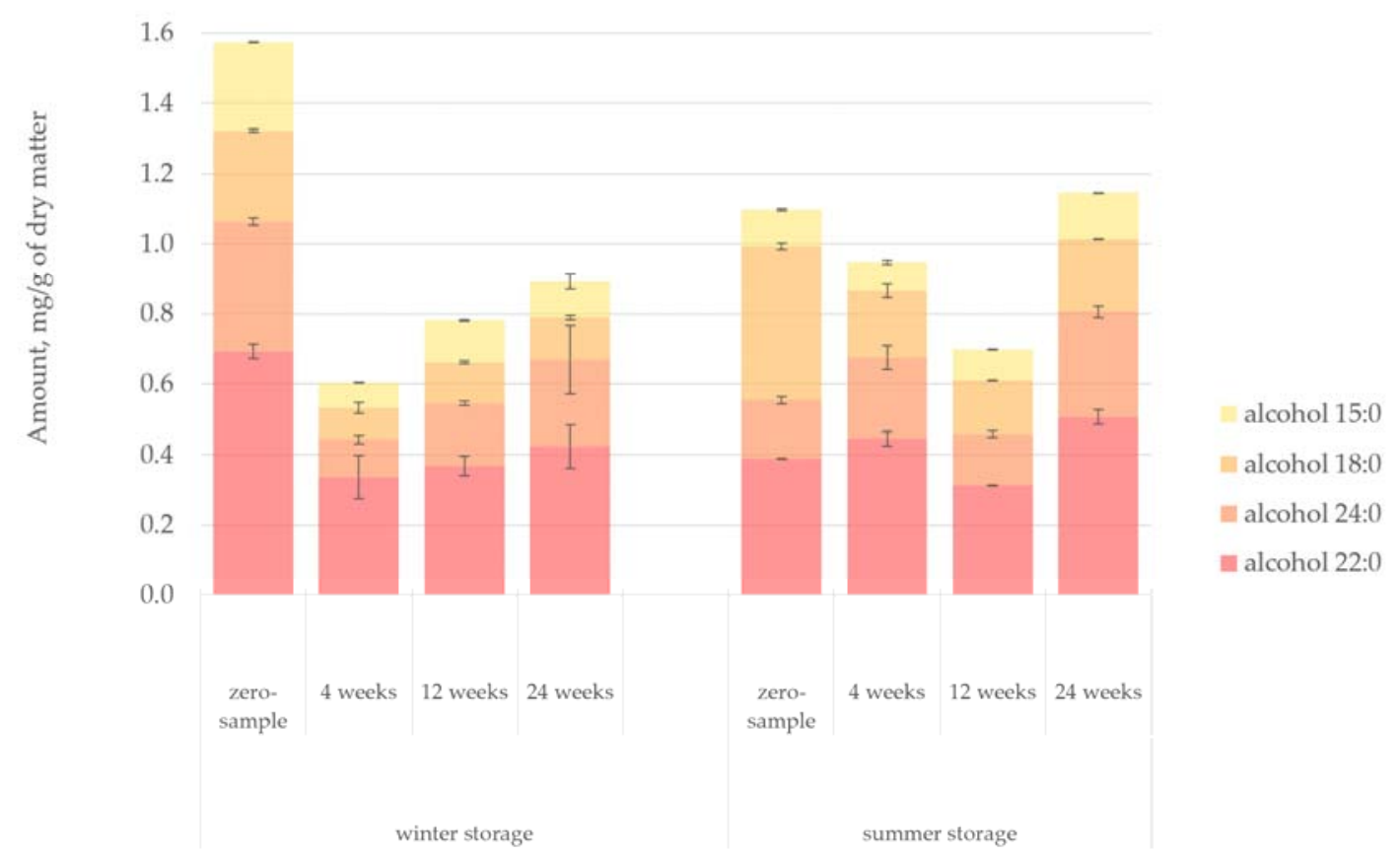

Figure 10. Changes in fatty alcohols during summer and winter storage periods of saw log bark.

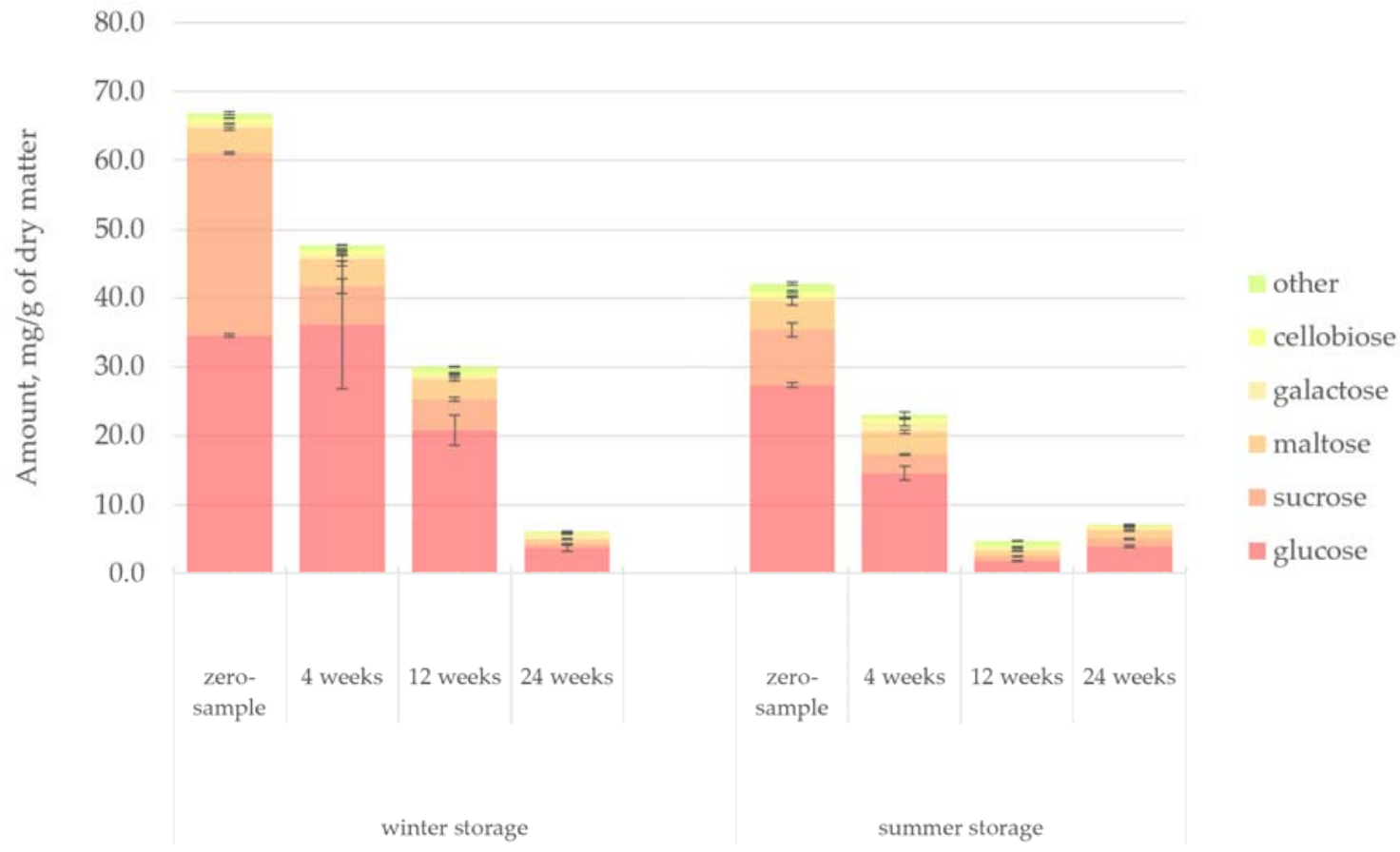

Figure 11. Changes in sugars during summer and winter storage periods of saw log bark.

Figure 7 presents the quantified amount of fatty acids in the lipophilic bark extracts. The rate of fatty acid degradation followed a quite predictable path in both storage studies. The initial amount of fatty acids was higher at the beginning of the summer storage period. However, fatty acids also decreased faster during summer, primarily due to increased hydrolysis, oxidation and reactions of conjugated double bonds. The sample from the winter storage period at week 12 appeared to be an anomaly, having a generally high concentration of fatty acids but also a much higher amount of acid 20:0 compared to other samples. The difference might be explained by the fact that, as seen in Table 1, the sample logs from the winter storage period at week 12 were around 30 years younger than the 
average age of the trees used in the study. The same observation was true for the zerosample saw logs from the summer storage period, which had an equally high concentration of fatty acids. This result suggested that a tree's age influences the amount of fatty acids in spruce bark. For this study, having a significant variance in tree age was an interesting factor to note but not an objective that was pursued. For meaningful inferences from tree age to extractives content to be made, the number of samples would have needed to be significantly higher. As a general principle, older trees have more resin in the heartwood. Moreover, while this behaviour could also be expected of bark, the authors of this paper are not aware of any studies that carefully demonstrate the relationship between tree age and the total extractives content of Norway spruce bark.

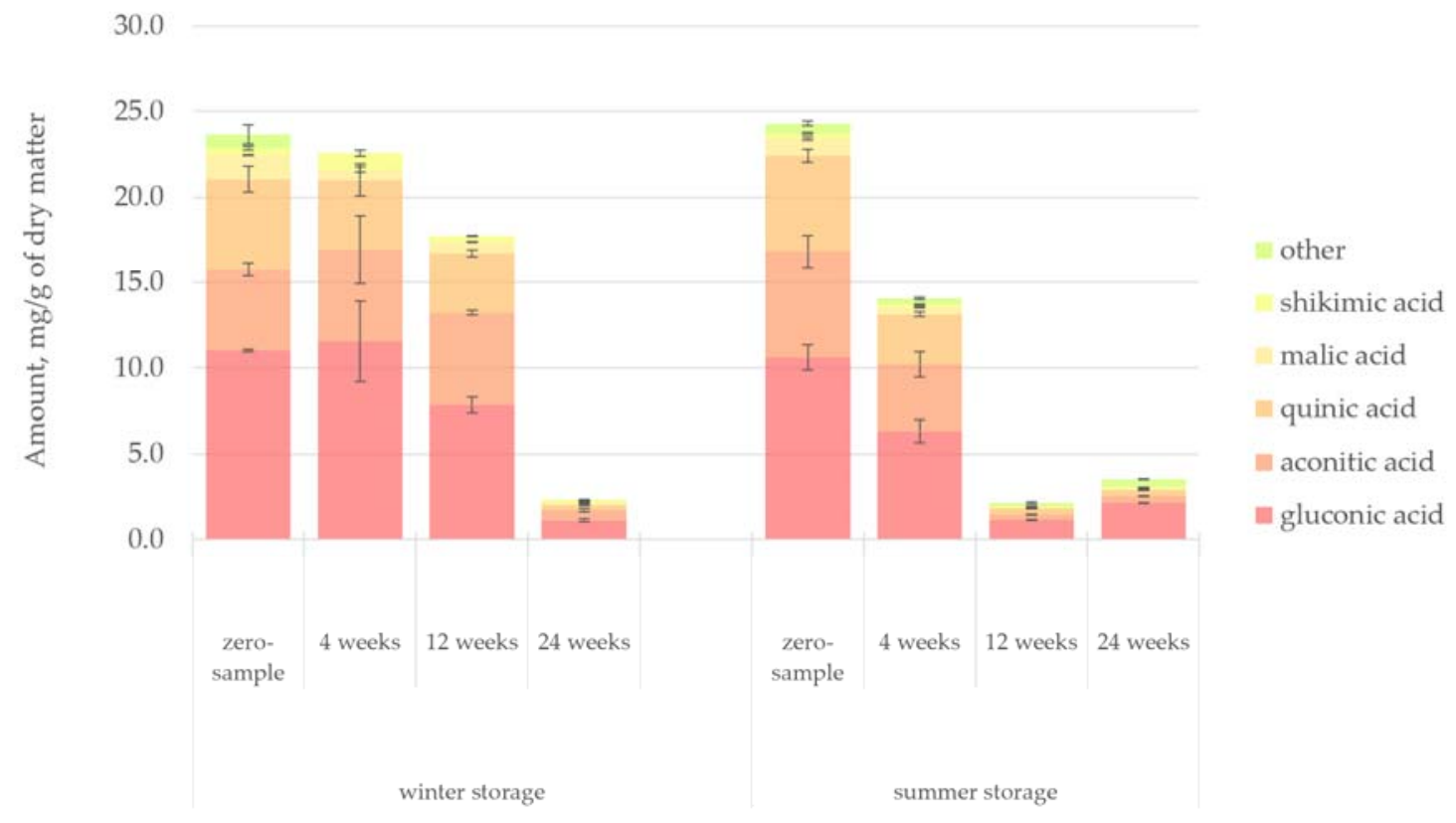

Figure 12. Changes in organic acids during summer and winter storage periods of saw log bark.

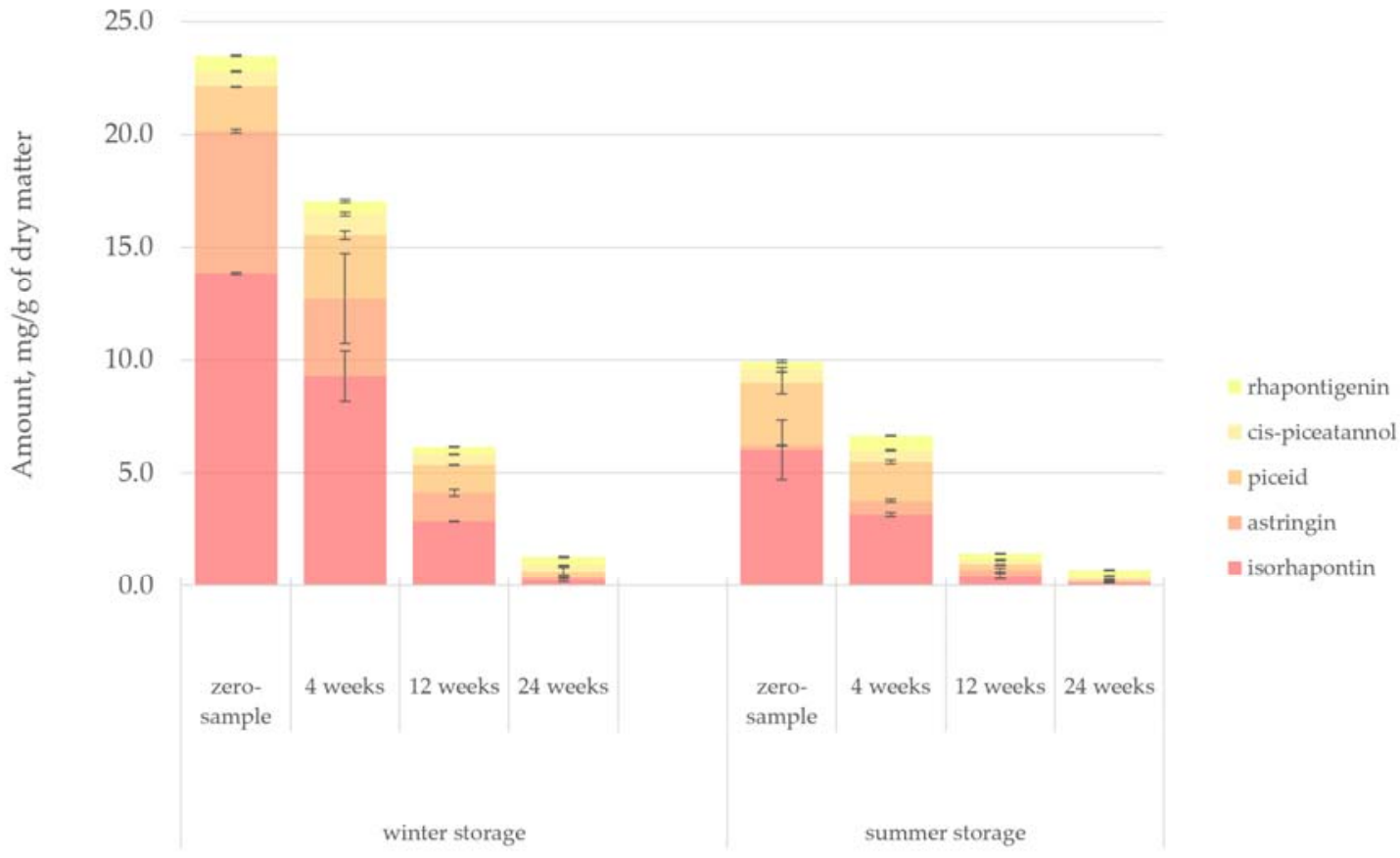

Figure 13. Changes in stilbenes during summer and winter storage periods of saw log bark. 


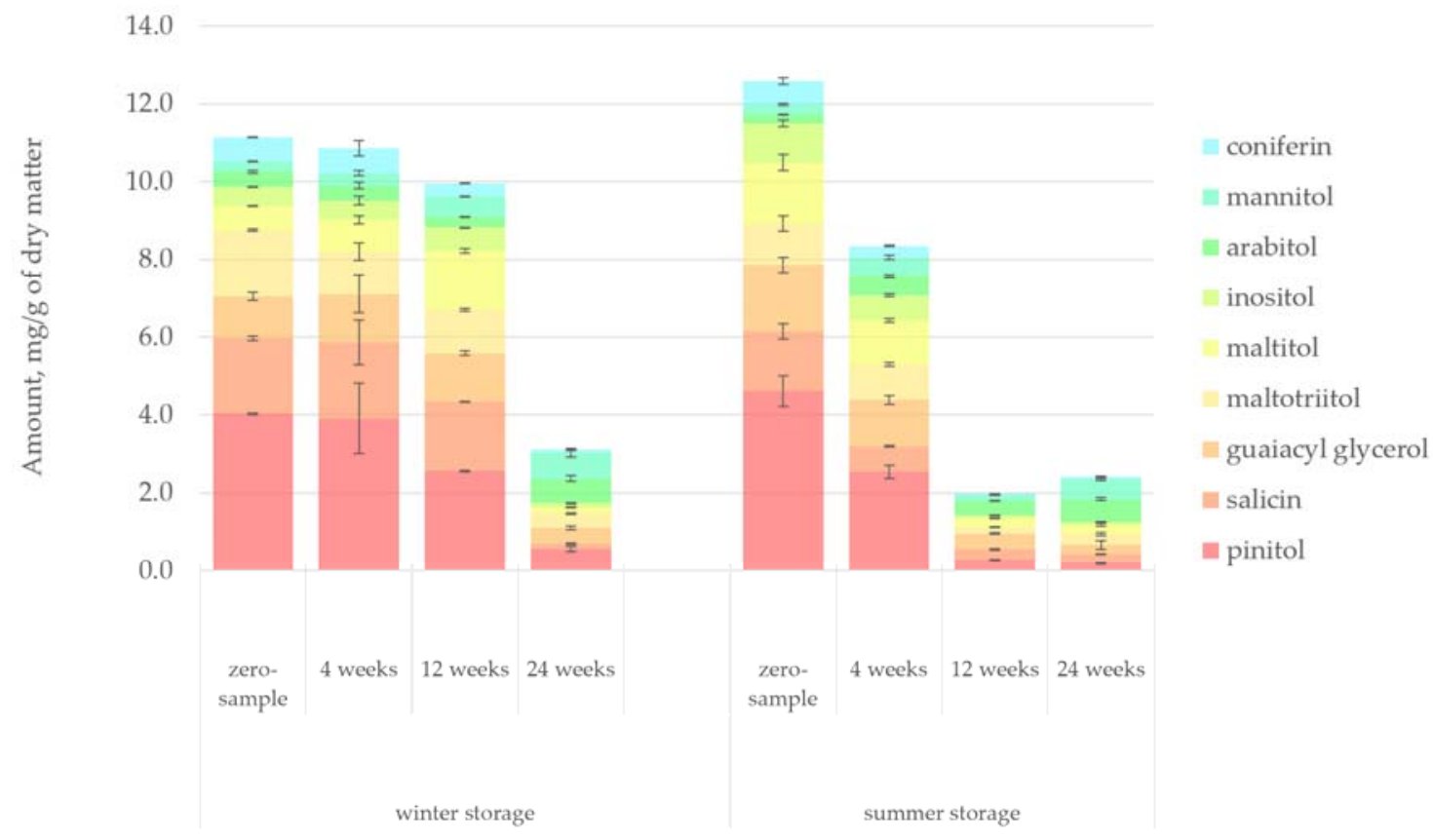

Figure 14. Changes in alcohols during summer and winter storage periods of saw log bark.

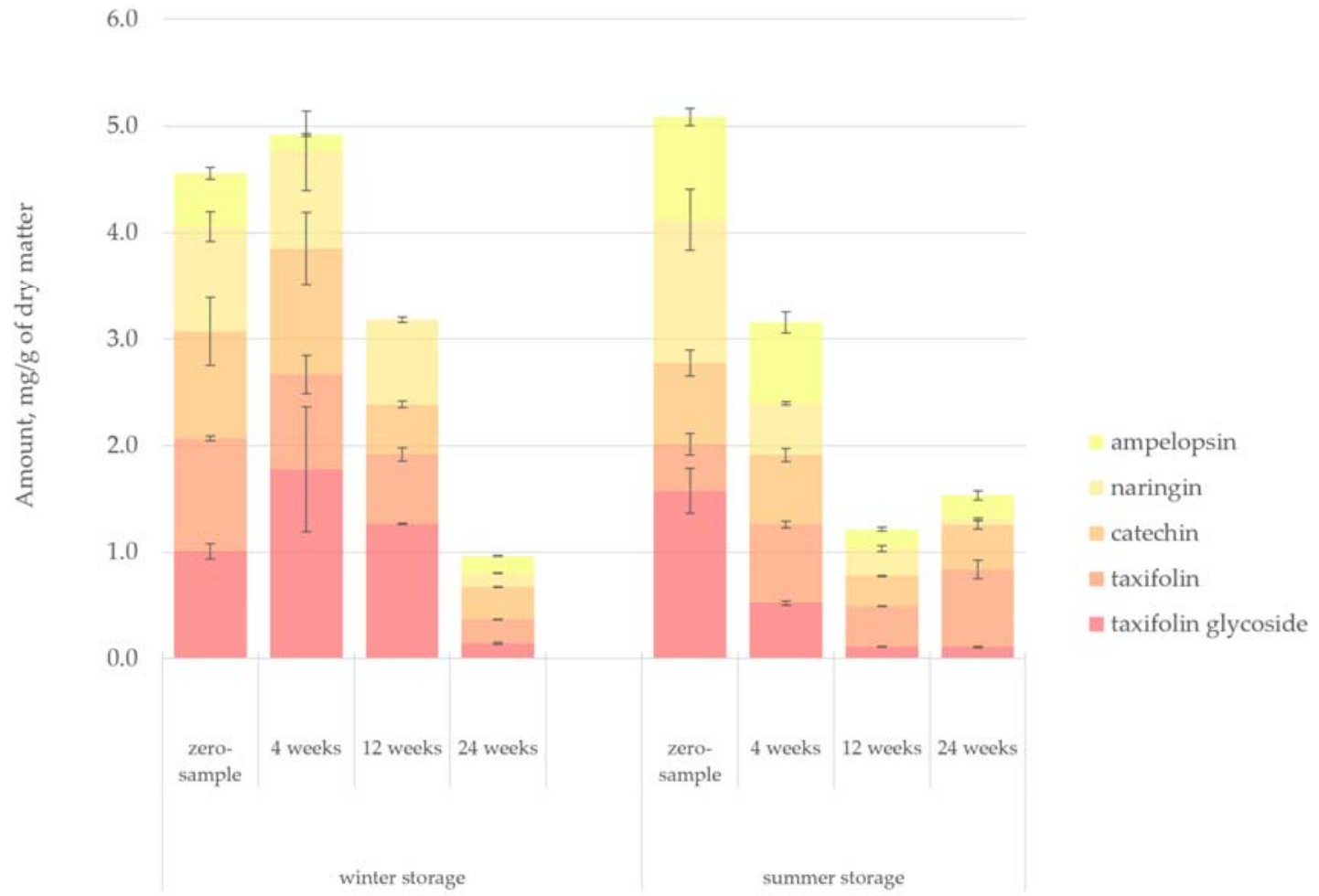

Figure 15. Changes in flavonoids during summer and winter storage periods of saw log bark.

Figure 8 presents the quantified amount of diterpenoids in the lipophilic bark extracts. The total amount of diterpenoids was higher during the summer storage period, especially the amount of manool and thunbergol. Nevertheless, the amount of cubebene appeared to be higher during the winter storage period. As noted before regarding resin acids, samples at week 4 had particularly low concentrations. Despite this variation, the total amount of diterpenoids slowly decreased as the storage period lengthened.

Figure 9 presents the quantified amount of sterols in the lipophilic bark extracts. 
Sitosterol was the most significant and abundant sterol in spruce bark, while campesterol was overall the second abundant, remaining relatively constant in all samples. Diglycerol appeared with a high concentration on the zero-samples of the winter-stored bark. However, its amount was quickly reduced as the storage period continued and the ambient temperature rose. During the summer storage period, diglycerol could not be detected even at the zero-sample.

Figure 10 presents the quantified amount of fatty alcohols in the lipophilic bark extracts. The degradation pattern of fatty alcohols in the bark samples paralleled the degradation pattern of sterols, more or less. Particularly high concentration of fatty alcohols (especially alcohol 22:0) was observed at the beginning of the winter storage period. On the other hand, the zero-sample from the summer storage period had a notably high concentration of alcohol 18:0. Although the total amount of fatty alcohols remained stable, after the initial decrease in the amount of fatty alcohols, there appeared to be a slight increase until the end of the storage period. This increase could be explained by the gradual conversion of fatty acids or triglycerides into fatty alcohols.

Figure 11 presents the quantified amount of sugars in the hydrophilic bark extracts. The results indicated that the concentration of simple sugars in the extracts decreased systematically and significantly. Similar results have been reported in storage studies of wood [45]. Glucose and sucrose alone made up most of the detected sugars. A clear difference could be noticed in the initial sugar concentration between the winter- and summer-stored bark. The winter-stored bark had a 37\% higher sugar concentration initially. Saccharides are especially prone to degradation since they could easily be leached out by rain and provide an excellent nutrient source for micro-organisms. The enhanced activity of micro-organisms during warm seasons also explains the more significant reduction of saccharides observed during the summer storage period.

Figure 12 presents the quantified amount of organic acids in the hydrophilic bark extracts. Gluconic, aconitic and quinic acids accounted for most of the organic acids present in the hot-water extract of spruce bark. Gluconic acid was found to be the most abundant organic acid, probably related to the high glucose level in the bark samples. It has been shown that gluconic acid may be obtained by the oxidation of glucose catalysed by the glucose oxidase enzyme [46]. The degradation pattern of organic acids followed that of the sugars, although the initial amount of organic acids in bark during storage was not affected by season. The degradation of organic acids was slower than that of sugars, but again a clear difference in degradation rate was observed between the winter and summer storage. The winter-stored bark retained $76 \%$ of the original amount of organic acids until 12 weeks of storage, while there was a $42 \%$ decrease in the concentration of the organic acids during the first 4 weeks of the summer storage period.

Figure 13 presents the quantified amount of stilbene glucosides (by long column GC-FID) in the hydrophilic bark extracts. Stilbenes from conifer bark have been the focus of many previous studies, giving them promise as platform chemicals and antifungal agents [2,25,32,47-49]. The three primary stilbene glucosides in spruce bark, isorhapontin, astringin and piceid, along with the stilbene aglycones cis-piceatannol and rhapontigenin, were identified. The total amount of stilbenes was $23.5 \mathrm{mg} / \mathrm{g}$ of dry bark in the winter storage zero-sample and $9.9 \mathrm{mg} / \mathrm{g}$ of dry bark in the summer storage zero-sample. Gabaston et al. [32] reported a similar concentration $(18.5 \mathrm{mg} / \mathrm{g}$ of bark) in a sample stored for 1 month in the dark. On the other hand, much higher stilbene concentrations have been reported on the root bark of Norway spruce [48].

The degradation of the stilbene glucosides and aglycones in the bark samples followed a similar pathway as seen for the sugars. The evident influence of the season was seen in that the zero-sample of the summer-stored bark contained 58\% fewer stilbenoids than the zero-sample of the winter-stored bark. However, the degradation rate of stilbenoids was approximately the same during both winter and summer.

Stilbenes are known for being sensitive to UV light and may easily undergo photocatalysed cis/trans isomerisation and rearrangement reactions to form phenanthrene 
structures $[17,18,50]$. Because of exposure to an increased amount of UV light and higher temperatures during the summer storage period, the loss of stilbenes would be expected to be amplified. Lesions exposing the inner bark (e.g., those caused during harvesting) would be expected to increase stilbenes' degradation because they are primarily located on the inner bark [49]. Increased microbiological activity during summer also explains the reduction of stilbenes because, although stilbenoids are antimicrobial by nature, they are not inert to microbial or enzymatic degradation. The increased UV light appeared to have a particularly significant effect on the level of the stilbenoid astringin. Astringin had a substantially lower concentration during the summer, but during winter, it was the second most abundant stilbenoid after isorhapontin.

Figure 14 presents the quantified amount of alcohols in the hydrophilic bark extracts. The degradation pattern of alcohols in the saw log bark during storage closely resembled that of organic acids. Most of the alcohols found in the hot-water extract, including pinitol, maltotriitol, maltitol, inositol, arabitol and mannitol, were sugar alcohols. It was evident that temperature dramatically affected the reduction of alcohols. During the winter storage period, until week 12 (i.e., when the ambient temperature according to Figure 2 was approximately $5^{\circ} \mathrm{C}$ ), the amount of alcohols remained relatively high. However, during the summer storage period, the amount of alcohols decreased by $34 \%$ immediately after 4 weeks of storage. The slight increase in the level of alcohols during the summer storage period from week 12 to 24 (a similar pattern as was seen for organic acids, sugars and flavonoids) could be explained by the natural variance between the saw logs (e.g., the age of the trees). However, the decrease in the summer storage ambient temperature from week 12 to 24 (from $13{ }^{\circ} \mathrm{C}$ to $0{ }^{\circ} \mathrm{C}$ according to Figure 2) could also explain the results.

Figure 15 presents the quantified amount of simple flavonoids in the hydrophilic bark extracts. Among the identified flavonoids, a remarkably similar degradation pattern to alcohols was observed. However, flavonoids appeared to be more sensitive than alcohols to ambient temperature increase towards the end of the winter storage period. The amount of identified flavonoids was quite insignificant compared to other extractives groups, although it should be noted that the compound group designated as 'others' (in Figure 5) most likely included several unidentified flavonoid derivatives. The identification of individual flavonoids from bark extracts was especially challenging because of the myriad of compounds that were eluted at the same time during the GC-MS analysis (Figure A4). All of the identified flavonoids eluted approximately at the retention time of 40-50 min, containing many overlapping peaks.

\subsubsection{Quantitative and Qualitative Analysis by HPLC}

The used HPLC method was targeted specifically for the identification and quantification of stilbenes from the bark extract. A tentative identification and quantification of several stilbene monomers and dimers were achieved based on the compounds' mass fragmentation. The qualitative and quantitative results are presented in Table 5, and possible structures for some of the compounds are suggested in Appendix B Figure A6. Similar molecular structures have also been suggested for stilbene dimers in earlier studies $[32,47,51]$. The qualification and quantification of stilbenes were done for the zerosample and the sample of the winter-stored saw logs stored for 24 weeks. The quantification was undertaken via external standard trans-piceid. A standard calibration curve with concentrations ranging from $1 \mu \mathrm{g} / \mathrm{mL}$ to $40 \mu \mathrm{g} / \mathrm{mL}$ was prepared with a good linearity and correlation coefficient $R^{2}$ with the value of 0.9991 . 
Table 5. The qualitative and quantitative results of the high-performance liquid chromatography (HPLC) analysis of bark hot-water extract.

\begin{tabular}{|c|c|c|c|c|c|c|}
\hline \multirow{2}{*}{$\begin{array}{l}\text { Retention Time } \\
\text { (min) }\end{array}$} & \multirow{2}{*}[\mathrm{M}-\mathrm{H}]{$\mathrm{m} / z$} & \multirow{2}{*}{$\begin{array}{l}\text { Main Fragments } \\
\qquad(\mathrm{m} / \mathrm{z})\end{array}$} & \multirow{2}{*}{$\begin{array}{c}\text { Tentative } \\
\text { Identification }\end{array}$} & \multicolumn{2}{|c|}{ Amount (mg/g of Dry Matter) } & \multirow{2}{*}{ Change (\%) } \\
\hline & & & & Zero-Sample & After 24 Weeks & \\
\hline 7.6 & 405 & $811,473,243$ & astringin & 8.8 & 1.5 & -82.5 \\
\hline 9.7 & 389 & $809,567,435,299,227$ & trans-piceid & 3.7 & 1.7 & -52.6 \\
\hline \multirow[t]{2}{*}{10.5} & 419 & $839,465,257$ & trans-isorhapontin & 14.7 & 2.3 & -84.6 \\
\hline & \multicolumn{3}{|c|}{ Total stilbenoid monomers } & 27.1 & 5.5 & -79.6 \\
\hline 11.5 & 823 & $707,665,299$ & isorhapontin dimer 1 & 2.5 & 1.3 & -49.6 \\
\hline 12.3 & 809 & $845,575,541,299,187$ & astringin dimer 1 & 1.1 & 0.6 & -45.5 \\
\hline 12.5 & 809 & $823,555,163$ & astringin dimer 2 & 2.1 & 0.8 & -60.7 \\
\hline 13.3 & 823 & $859,555,299$ & isorhapontin dimer 2 & 3.1 & 4.8 & 58.4 \\
\hline \multirow[t]{3}{*}{14.6} & 837 & 569,299 & isorhapontin dimer 3 & 1.9 & 1.9 & 0.1 \\
\hline & \multicolumn{3}{|c|}{ Total stilbenoid dimers } & 10.8 & 9.5 & -11.7 \\
\hline & \multicolumn{3}{|c|}{ Total stilbenoids (monomers and dimers) } & 37.9 & 15.0 & -60.3 \\
\hline
\end{tabular}

The three stilbene glucosides, trans-isorhapontin, astringin and trans-piceid, were the most prominent of the identified stilbenoids. Small amounts of several dimeric stilbenoid species were also recognised, at least three of which were assumedly based on dimeric isorhapontin and two on dimeric astringin species. These results also facilitated identifying the compounds in Figure A5 with the retention time range of 16-18 min as dimeric stilbenoids. In the zero-sample, trans-isorhapontin was the most abundant of the identified monomeric stilbenoids ( $14.7 \mathrm{mg} / \mathrm{g}$ of dry matter), astringin came second $(8.8 \mathrm{mg} / \mathrm{g}$ of dry matter) and trans-piceid third ( $3.7 \mathrm{mg} / \mathrm{g}$ of dry matter). These results agreed with those obtained by GC-MS, although the HPLC samples' reported amount was slightly higher. This difference could be explained by the fact that in comparison to GC, the HPLC method is more sensitive, the sample preparation for analysis is more straightforward and the delay between extraction and identification of the compounds is shorter. Hence, less degradation and error due to sample treatment occurred.

Among the identified stilbenoids, dimeric stilbenoids were the least abundant. The dimeric species with the main fragment of $m / z 823$ were identified as isorhapontin dimers 1 and 2, which were the most abundant in the zero-sample at $2.5 \mathrm{mg} / \mathrm{g}$ and $3.1 \mathrm{mg} / \mathrm{g}$ of dry matter, respectively. Other dominant dimeric species were those with the main fragment $m / z 809$, identified as astringin-based stilbene dimers, and one with the main fragment $m / z 837$, identified as isorhapontin dimer 3 .

If the dimeric species were accurately identified, it would suggest that trans-piceid does not form similar dimeric species as do astringin and trans-isorhapontin. This would be understandable since, in the proposed structures for the dimeric species, the ether bonds connecting the monomeric species are formed via the two phenolic hydroxyl/methoxy groups of astringin and isorhapontin (at ring B; see Appendix B Figure A6). Because trans-piceid only has one phenolic hydroxyl group in ring B, it would only form single ether bonds, which are not as strong.

As shown in Table 5, there was approximately a $60 \%$ decrease in the total amount of the identified stilbenoids. The degradation of stilbenoid monomers and that of dimers was not, however, equal. The monomers decreased by almost $80 \%$, while the dimers decreased by only around $10 \%$. It should be noted that some of the dimeric species were more abundant at the end of the storage period. The amount of isorhapontin dimer 2 increased by almost $60 \%$. This result may indicate that polymerisation reactions play an essential role in the degradation of stilbenoids. However, evaluating the mechanisms of the polymerisation reactions (whether they be enzymatic in nature or something else) was not within the scope of this study.

When looking at both dimeric and monomeric species, it appears that overall astringinrelated stilbenoids corresponded with the most significant losses during storage. This observation was also confirmed by the GC results (Figure 13), especially during the sum- 
mer storage period, where even the initial amount of astringin in the zero-sample was vanishingly small and reached undetectable levels by week 24 of the storage period. The loss of astringin might be explained by the fact that, of the stilbenoid monomers, astringin has the highest amount of the free phenolic hydroxyl groups, which is known to increase reactivity and antioxidant activity.

\subsection{Change in Carbohydrate and Lignin Content}

The results from the carbohydrate and lignin analysis of the bark samples are shown in Table 6. The carbohydrate content was measured from the extractives-free bark at the beginning and the end of the storage period. For each set of extractives-free bark, two samples were taken for carbohydrate analysis. Since the extractions were duplicated, the carbohydrate results for each week were presented as the mean values from four measurements. The cellulose content presented in Table 6 was calculated as the difference between the monosaccharide content (from acid hydrolysis) and the hemicellulose content (from acidic methanolysis). The compounds designated as 'others' were the solid leftovers unexplained by the methods used and were calculated by subtracting the total carbohydrate and lignin content from the samples' dry mass. This group presumably contained inorganic compounds.

Table 6. Change in chemical composition of extractives-free spruce bark during storage (\% of dry matter).

\begin{tabular}{ccccccc}
\hline & $\begin{array}{c}\text { Storage Time } \\
\text { (Weeks) }\end{array}$ & Cellulose & Hemicelluloses & $\begin{array}{c}\text { Acid-Insoluble } \\
\text { Lignin }\end{array}$ & $\begin{array}{c}\text { Acid-Soluble } \\
\text { Lignin }\end{array}$ & Others \\
\hline Winter storage & 0 & $25.8 \pm 5.4$ & $26.1 \pm 2.4$ & $35.1 \pm 3.4$ & $1.6 \pm 0.03$ & $11.5 \pm 4.6$ \\
& 24 & $14.6 \pm 0.4$ & $33.2 \pm 3.9$ & $32.2 \pm 1.0$ & $1.3 \pm 0.05$ & $18.8 \pm 1.1$ \\
\hline Summer & 0 & $22.0 \pm 3.1$ & $22.9 . \pm 2.4 *$ & $40.8 \pm 2.5$ & $1.3 \pm 0.1$ & $13.0 \pm 0.8$ \\
storage & 24 & $7.3 \pm 3.1$ & $36.4 \pm 3.3$ & $37.8 \pm 0.6$ & $1.2 \pm 0.03$ & $17.3 \pm 3.7$ \\
\hline
\end{tabular}

* A result based on a duplicate sample, while other hemicellulose results were based on four samples.

According to Table 6, at the beginning of the winter storage period, $51.9 \%$ of the extractives-free bark was made up of carbohydrates (i.e., hemicelluloses and cellulose), and $44.9 \%$ at the beginning of summer storage. On the other hand, the total lignin amount was $36.7 \%$ at the beginning of the winter storage period and $42.1 \%$ at the beginning of the summer storage period. At the end of the 24-week storage periods, the total carbohydrate content was $47.7 \%$ and $43.7 \%$ during winter and summer, respectively. At the end of the 24-week storage period, the total lignin content was 33.5\% and 39.0\% during winter and summer, respectively. The total carbohydrate and lignin content remained relatively stable, ensuring the bark's value, for example, for bioenergy production. These results might be somewhat misleading in that they only deal with the remaining bark on the saw logs and do not consider the total material losses. The total mass losses could not be evaluated by direct observation as the bark needed to remain intact on the saw logs and could not be removed until the sampling.

Table 6 shows that the carbohydrate and lignin content changes in the bark samples followed similar trends both during the summer and winter storage periods. At the beginning of the storage periods, the hemicellulose content was $0.4 \%$ and $2.4 \%$ higher than the cellulose content during winter and summer, respectively. The amount of hemicellulose increased by $7.1 \%$ and $13.5 \%$ during the winter and summer storage periods, respectively. The cellulose content decreased by $11.2 \%$ and $13.2 \%$ during the winter and summer storage periods, respectively. Hence, at the end of the 24-week storage periods, the hemicellulose content was $18.7 \%$ and $29.1 \%$ higher than the cellulose content during winter and summer, respectively.

At the beginning of the storage periods, the amount of acid-insoluble lignin was $33.5 \%$ and $39.5 \%$ higher than the amount of acid-soluble lignin during winter and summer, respectively. The amount of acid-insoluble lignin decreased by $2.9 \%$ and $3.0 \%$ during winter and summer, respectively. The amount of acid-soluble lignin decreased by only 
$0.3 \%$ and $0.1 \%$ during winter and summer, respectively. The amount of other compounds increased by $7.3 \%$ and $2.8 \%$ during winter and summer, respectively.

The results indicated that the content of cellulose, hemicelluloses and acid-soluble lignin in the bark was lower during the summer storage period, while the amount of acid-insoluble lignin was higher during the summer storage period. The observed decrease of the cellulose content during the storage periods could be explained by the ceasing of the active natural protective measurements (for example, synthesis of protective compounds) of trees after their felling (due to lack of nutrients) against microbial and enzymatic activity as well as their exposure to UV light and weather. The lower initial level and higher degradation rate of cellulose during the summer storage period could be primarily explained by the increased amount of UV light and higher temperatures, which in turn would have enabled more microbial and enzymatic activities.

\subsubsection{Changes in Monosaccharide Content}

The HPAEC results shown in Figure 16 indicate changes in the content of bark monosaccharides in the acid hydrolysate. The results show that the glucose units were the most prevalent in the samples throughout the storage periods, making up $30-36 \%$ of the extractives-free bark, while the arabinose, mannose, xylose and galactose units accounted for $5-7 \%, 1-4 \%, 3-4 \%$ and $2-3 \%$ of dry matter, respectively. The released monosaccharide units were $5.5 \%$ more abundant during the winter storage period as opposed to the summer storage period. The storage had the most significant effect on the loss of glucose units. It should be noted that, in their native state, most monosaccharide units presented here exist either as oligomers and polymers or as glycosylated units bonded to lignin and other polyphenolics.

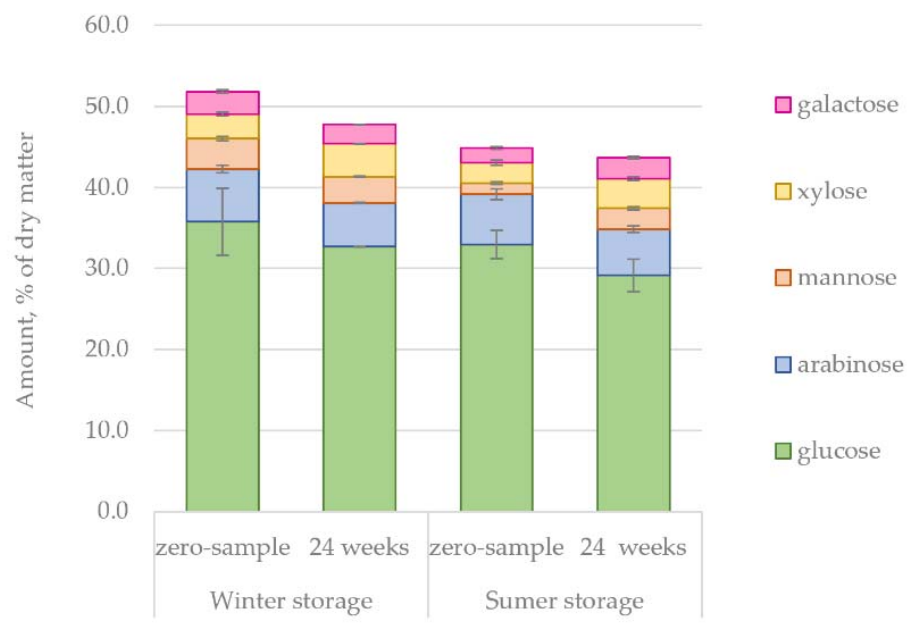

Figure 16. The high-performance anion-exchange chromatography (HPAEC) results of the changes in monosaccharide content during winter and summer storage.

\subsubsection{Change in Hemicellulose Content}

The changes in the hemicellulose content of extractives-free spruce bark during storage were determined by acidic methanolysis. The analysis results presented in Figure 17 indicated similar trends in winter- and summer-stored bark. The relative proportion of the hemicellulose content in extractives-free bark increased gradually during the storage periods. Arabinose and galacturonic acid units were the most abundant units during the winter storage period, corresponding to $6-9 \%$ and $6-8 \%$ of dry matter, respectively. Arabinose, galacturonic acid (the main component of pectin) and glucose were the most abundant units during the summer storage period, totalling $5-8 \%, 4-9 \%$ and $6-9 \%$ of dry matter, respectively. The most noteworthy differences were detected in the amounts of glucose and glucuronic acid. During the summer storage period, the amount of glucose in hemicelluloses increased by $39 \%$, and the amount of glucuronic acid by $62 \%$. This could 
be seen as the result of cellulose's degradation as the microbial activity would increase towards the end of the storage period. However, it should be noted that the total amount of glucose in the extractives-free bark decreased during the storage periods (Figure 16) as well as in the water extracts (Figure 5). Correlation with the ambient temperature, increasing towards the end of the winter storage period and at the beginning of the summer storage period, can also be observed (Figure 2).

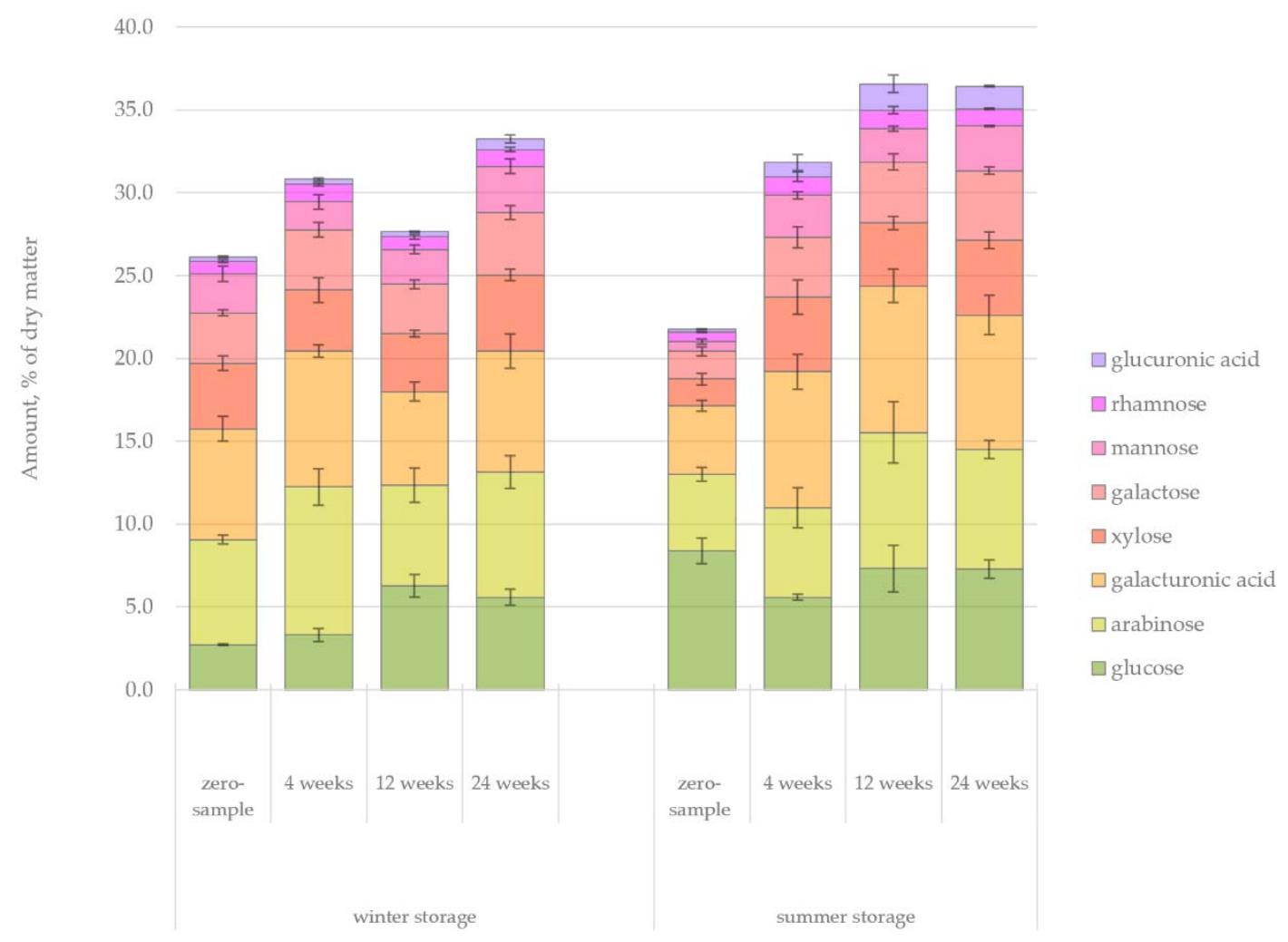

Figure 17. Changes observed in monosaccharide units of hemicelluloses during the winter and summer storage periods of spruce bark.

\subsection{Evaluation of Total Phenolic Content (TPC)}

The results indicating the total phenolic content (TPC) of the hot-water extracts, as evaluated with the Folin-Ciocalteu method, are shown in Figure 18. The TPC values are indicated in the figure by a blue dotted line. An overview of the results suggested that the level of TPC was $29 \%$ lower during the summer storage period, although the rate of degradation was quite similar in both experiments. The TPC value would presumably also contain the oligomeric and polymeric phenolic compounds. Thus, if the TPC results are compared with the amounts of phenolic compounds from the GC analyses (the columns in Figure 18), an estimate of polyphenols can be obtained. As can be seen, the estimated amount of polyphenols explained approximately $48 \%$ of the compounds left unidentified by GC. A large amount of the polyphenolic compounds would most likely contain polyphenols, such as lignin and condensed tannins. A more in-depth HPLC evaluation of the procyanidin content in the inner and outer bark of the same bark material has recently been published [25]. Those HPLC results appeared to be approximately $50 \%$ lower than the amounts of polyphenols estimated in Figure 18. This difference in results may be attributed to the presence of lignin and other reducing agents, which also affect the UV reading in the Folin-Ciocalteu method. The unidentified non-phenolic compounds, on the other hand, could contain, for example, polysaccharides. 


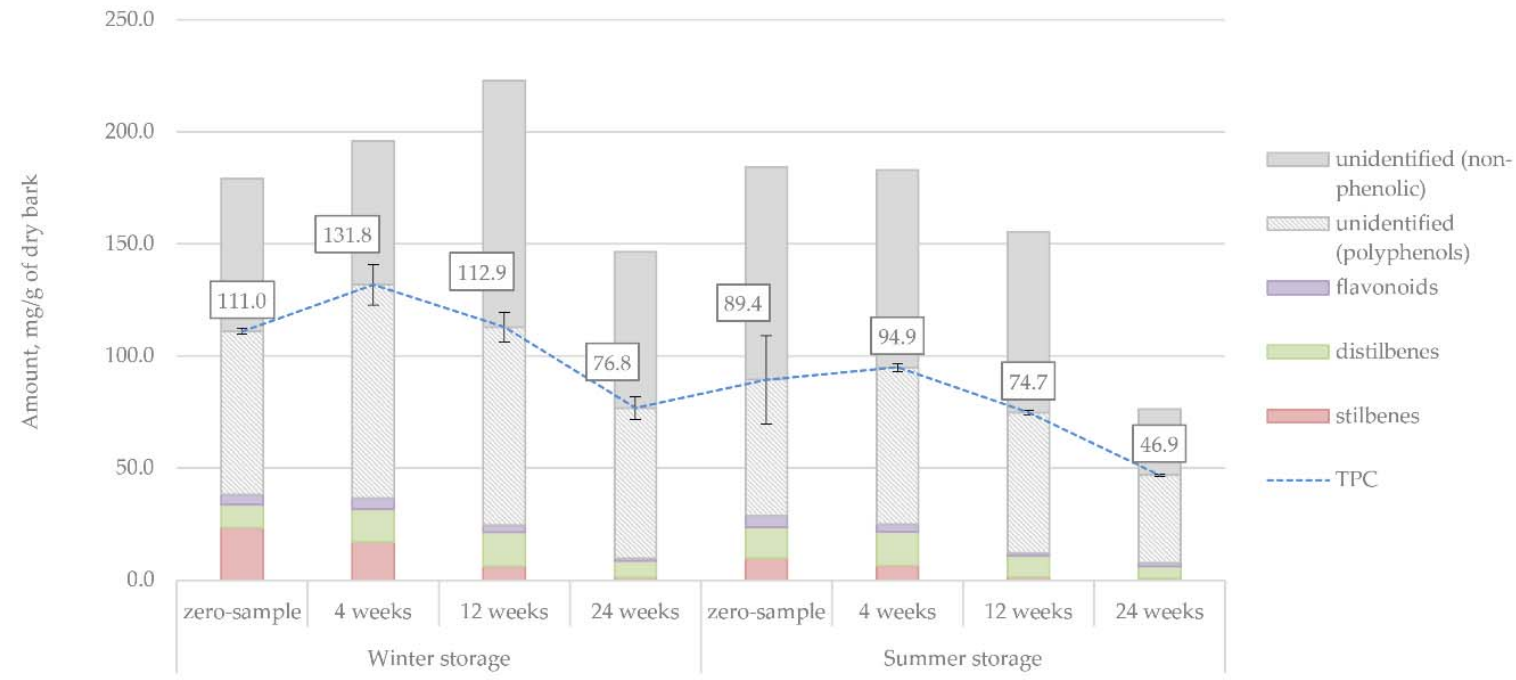

Figure 18. The total phenolic content (TPC) of the water extracts. The values of stilbenes, distilbenes, flavonoids and unidentified compounds from the GC analyses, as seen in Figure 5, are shown for reference.

\subsection{Results of the Statistical Analysis}

The $p$-values for the independent variables (season and storage time) are presented in Table 7. The results indicated that season has a statistically significant effect on the amount of triglycerides, steryl esters, sterols, stilbenes, alcohols, sugars, unidentified hydrophilic extractives and total phenols. Likewise, according to results, storage time has a statistically significant effect on the amount of resin acids, stilbenes, sugars, unidentified hydrophilic extractives and total phenols. The statistically significant results agree with what can be deduced from the quantification results. However, concerning some extractives groups, for example, flavonoids, the actual effect of storage time seems to be greater than what the statistical results can show.

Table 7. The statistical differences ( $p$-values) between storage time and season with regard to the quantitative amounts of extractive groups. Results showing statistical significance are bolded.

\begin{tabular}{ccc}
\hline Dependent Variable & $p$-Values for Independent Variables \\
\hline $\begin{array}{c}\text { Lipophilic extractives (gas chromatography with a } \\
\text { flame ionisation detector (GC-FID)) }\end{array}$ & Season & Storage time \\
\hline Resin acids & 0.247 & $\mathbf{0 . 0 3 7}$ \\
Fatty acids & 0.177 & 0.235 \\
Triglycerides & $\mathbf{0 . 0 0 7}$ & 0.460 \\
Diterpenoids & 0.143 & 0.137 \\
Sterols & $\mathbf{0 . 0 1 7}$ & 0.545 \\
Steryl esters & $\mathbf{0 . 0 2 0}$ & 0.458 \\
Fatty alcohols & 0.883 & 0.274 \\
Other & 0.130 & 0.124 \\
Unidentified & 0.930 & 0.752 \\
\hline Sugars & Season & Storage time \\
\hline Organic acids & $\mathbf{0 . 0 1 8}$ & $\mathbf{0 . 0 1 1}$ \\
Stilbenes & 0.408 & 0.190 \\
Sesquistilbenes & $\mathbf{0 . 0 1 2}$ & $\mathbf{0 . 0 0 4}$ \\
Distilbenes & $\mathbf{0 . 0 5 8}$ & 0.434 \\
Alcohols & 0.554 & 0.128 \\
Flavonoids & $\mathbf{0 . 0 2 0}$ & 0.313 \\
Other & 0.553 & 0.138 \\
Unidentified & 0.240 & 0.517 \\
\hline silic extractives (GC-FID) & $\mathbf{0 . 0 0 2}$ & $\mathbf{0 . 0 2 8}$ \\
\hline soectrometry) & $\mathbf{0 . 0 0 9}$ & $\mathbf{0 . 0 1 6}$ \\
\hline
\end{tabular}


Here only the main effect of storage concerning extractives groups was evaluated. To meaningfully evaluate the mixed effect of season and storage time statistically and consider the factors of tree age and sampling point and their effect on the behaviour of extractives would have required many more individual samples. This would be an interesting study for the future. However, for our purposes, to aid in the industrial-scale utilisation of bark, a more generalised look at extractives' behaviour during storage was feasible.

\section{Conclusions}

Seasonal variation is shown to affect the extractives content (predominantly hydrophilic compounds) of spruce bark obtained from stored saw logs. The compounds, which were the most sensitive to UV light and hydrolysis, degraded the fastest. For example, stilbenoid monomers were much more abundant during the winter storage period than during the summer storage period. An increase in ambient temperature also enhanced the microbial activity during summer, leading to higher extractives losses. The most apparent decrease of extractable compounds can be seen for hot water-extractable saccharides. The degradation patterns, especially for lipophilic extractives detected between the sample logs, were not always as straightforward and uniform as could be expected. Tree age, soil fertility and damage caused to bark (for example, during harvesting) could also significantly affect the extractives content and composition and explain some of the discrepancies observed between samples.

This study provided a comprehensive overview of how the extractives groups of spruce bark (both lipophilic and hydrophilic) behave while in storage. It has been demonstrated that high levels of extractives were retained in the bark of stored saw logs, especially during winter. This information could be particularly useful for parties interested in developing biorefinery concepts by utilising complex chemical biomass, such as bark, which would benefit from having a plan for the procurement and storage of the raw material. The development of high-value extractives-based products from conifer bark remains a potential prospect and an innovative undertaking. However, a great deal of time and energy could be saved if appropriate care is first taken to ensure the proper storage of raw material, which would maintain the quality of the extractives.

Supplementary Materials: The following are available online at https:/ / www.mdpi.com/article/10 $.3390 /$ f12060736/s1, Table S1: Values for Figure 4. Extractives groups in spruce bark hexane extract (amount, mg/g of dry bark), Table S2: Values for Figure 5. Extractives groups in spruce bark water extract (amount, mg/g of dry bark), Table S3: Values for Figure 6. Resin acids in spruce bark hexane extract (amount, mg/g of dry bark), Table S4: Values for Figure 7. Fatty acids in spruce bark hexane extract (amount, mg/g of dry bark), Table S5: Values for Figure 8. Diterpenoids in spruce bark hexane extract (amount, mg/g of dry bark), Table S6: Values for Figure 9. Sterols in spruce bark hexane extract (amount, mg/g of dry bark), Table S7: Values for Figure 10. Fatty alcohols in spruce bark hexane extract (amount, mg/g of dry bark), Table S8: Values for Figure 11. Sugars in spruce bark water extract (amount, mg/g of dry bark), Table S9: Values for Figure 12. Organic acids in spruce bark water extract (amount, mg/g of dry bark), Table S10: Values for Figure 13. Stilbenes in spruce bark water extract (amount, mg/g of dry bark), Table S11: Values for Figure 14. Alcohols in spruce bark water extract (amount, mg/g of dry bark), Table S12: Values for Figure 15. Flavonoids in spruce bark water extract (amount, mg/g of dry bark), Table S13: Values for Figure 16. Monosaccharides in extractives-free bark (amount, \% of dry matter), Table S14: Values for Figure 17. Hemicelluloses in extractives-free bark (amount, \% of dry matter), Table S15: Values for Figure 18. Total phenolic content (TPC) of water extracts.

Author Contributions: J.N.: funding acquisition, the conceptualisation of the study and writing (review and editing); H.E.B.: conceptualisation of the study, writing (review and editing) and supervision of experimental work; E.S.H.: writing (original draft preparation), chemical analysis, analysis method development, data analysis and interpretation and visualisation; O.L.: writing (review and editing) and conceptualisation of the study; R.A.: writing (review and editing) and supervision. All authors have read and agreed to the published version of the manuscript. 
Funding: The authors would like to express their gratitude for the funding received from the European Regional Development Fund, Interreg Botnia Atlantica, for the project BioHub (20200866), which made all the experimental work possible.

Institutional Review Board Statement: Not applicable.

Informed Consent Statement: Not applicable.

Data Availability Statement: Detailed data of the figures is available within the Supplementary Material. Other data is available upon request from the corresponding author.

Acknowledgments: Jaakko Miettinen, Tero Takalo, Reetta Kolppanen, and Anna Claydon are thanked for their skilful technical assistance in the laboratory and field. The authors would like to express their special thanks for the contribution of Nea Lintula for the analysis of the UV-Vis samples, Janne Kaseva and Maija Hujala for their valuable consultation on statistical analyses and the Finnish Meteorological Institute for providing access to the weather data.

Conflicts of Interest: The authors declare no conflict of interest.

\section{Appendix A. Chromatograms}

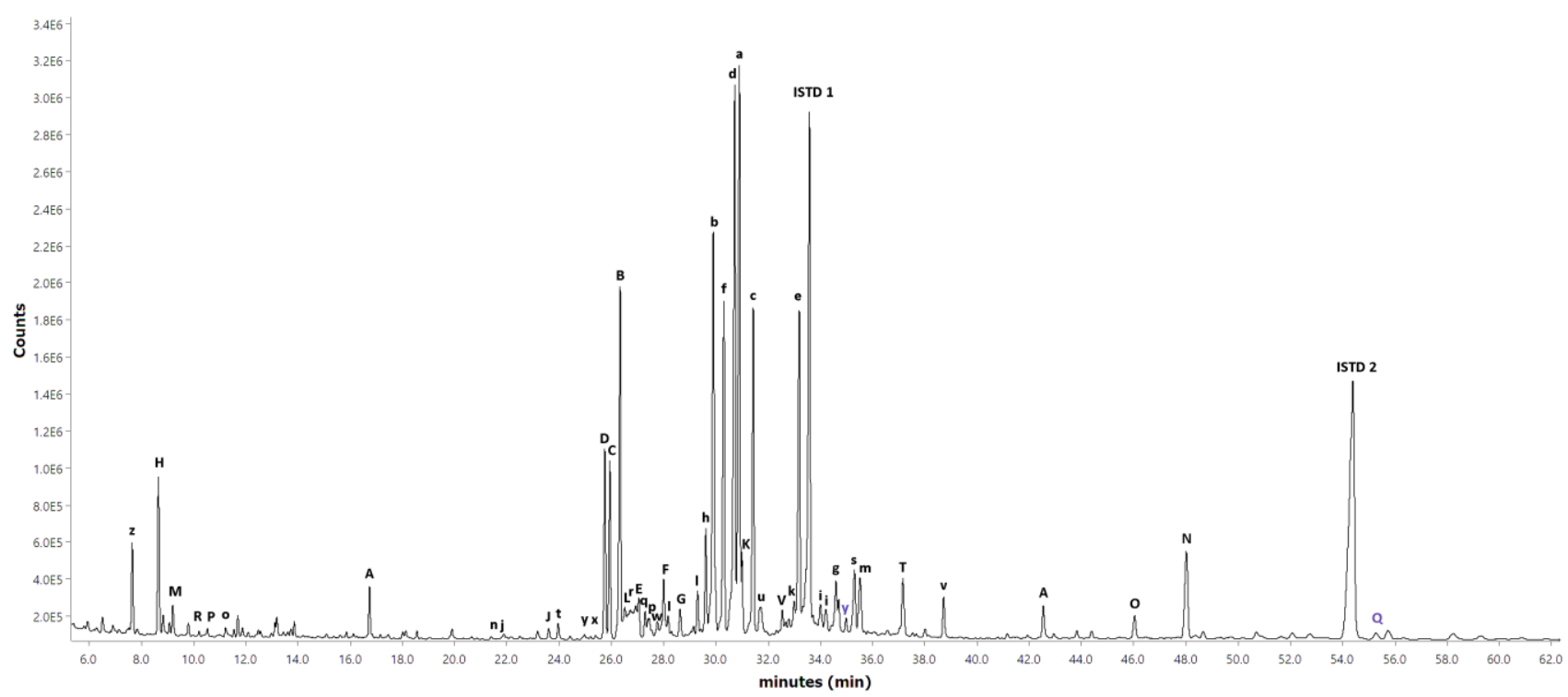

Figure A1. Reference gas chromatography with flame ionisation detection or mass spectrometry (GC-FID/MS) chromatogram for hexane extract of spruce bark. For alphabetical peak symbols, see Table 3. 


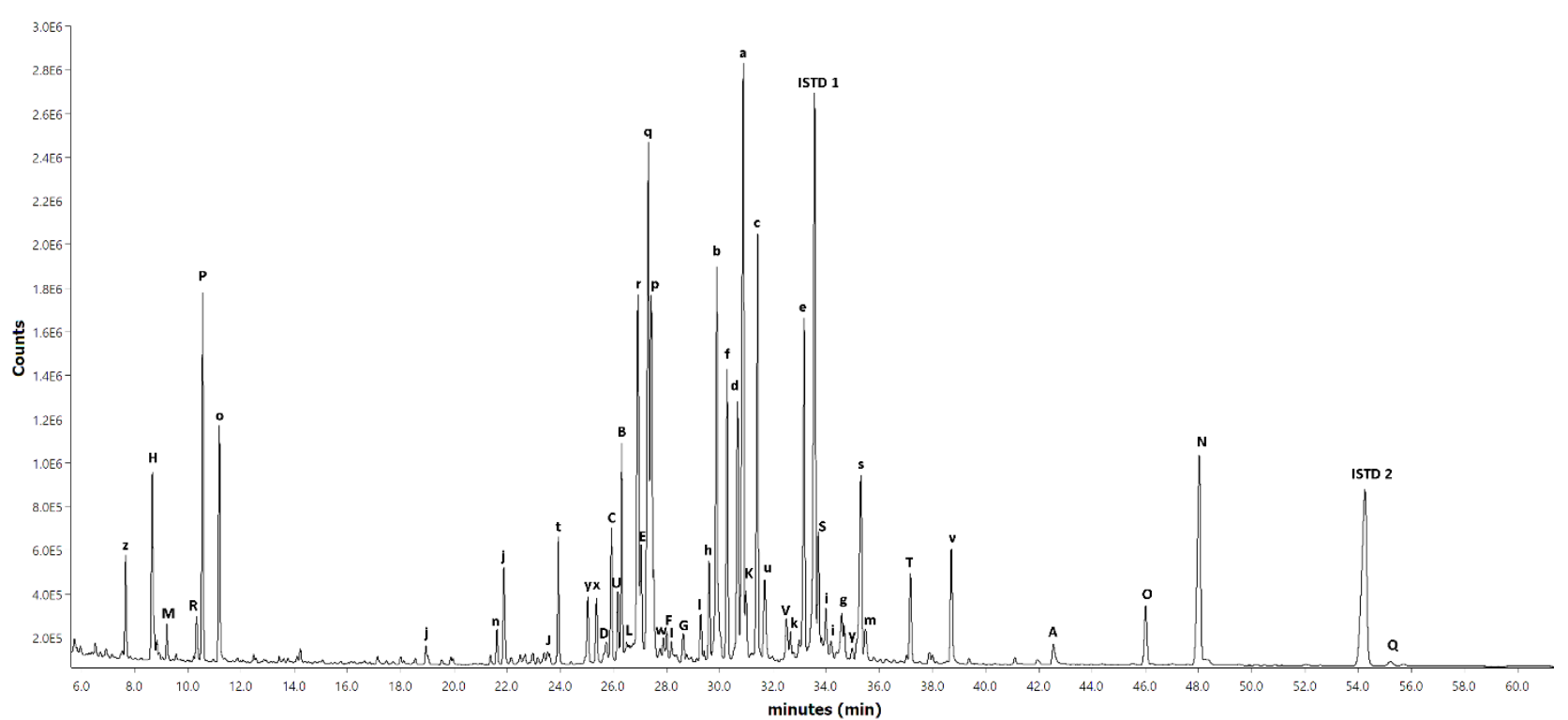

Figure A2. Reference gas chromatography with flame ionisation detection or mass spectrometry (GC-FID/MS) chromatogram for hexane extract of spruce bark (esterified compounds). For alphabetical peak symbols, see Table 3.

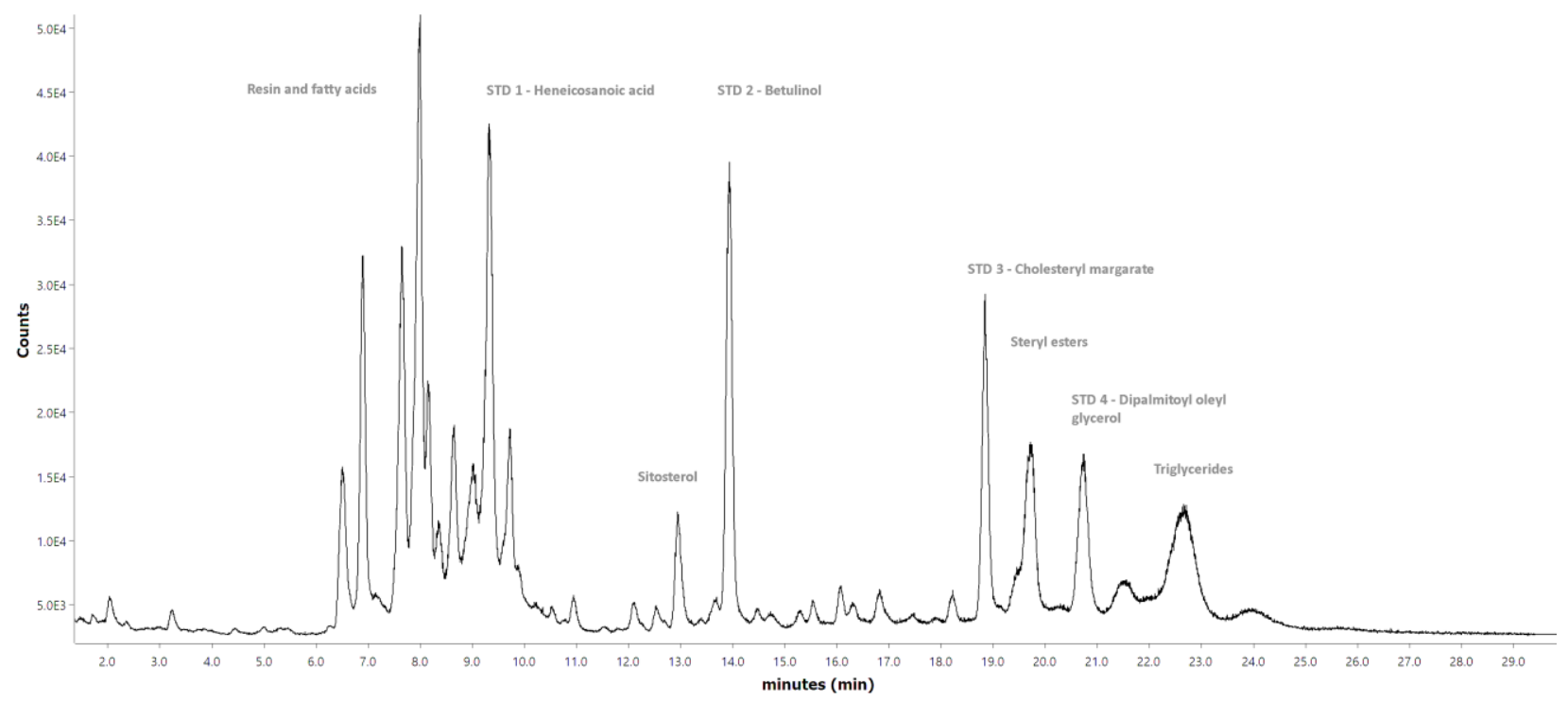

Figure A3. Reference gas chromatography with flame ionisation detection (GC-FID; short-column) chromatogram for hexane extract of spruce bark. 


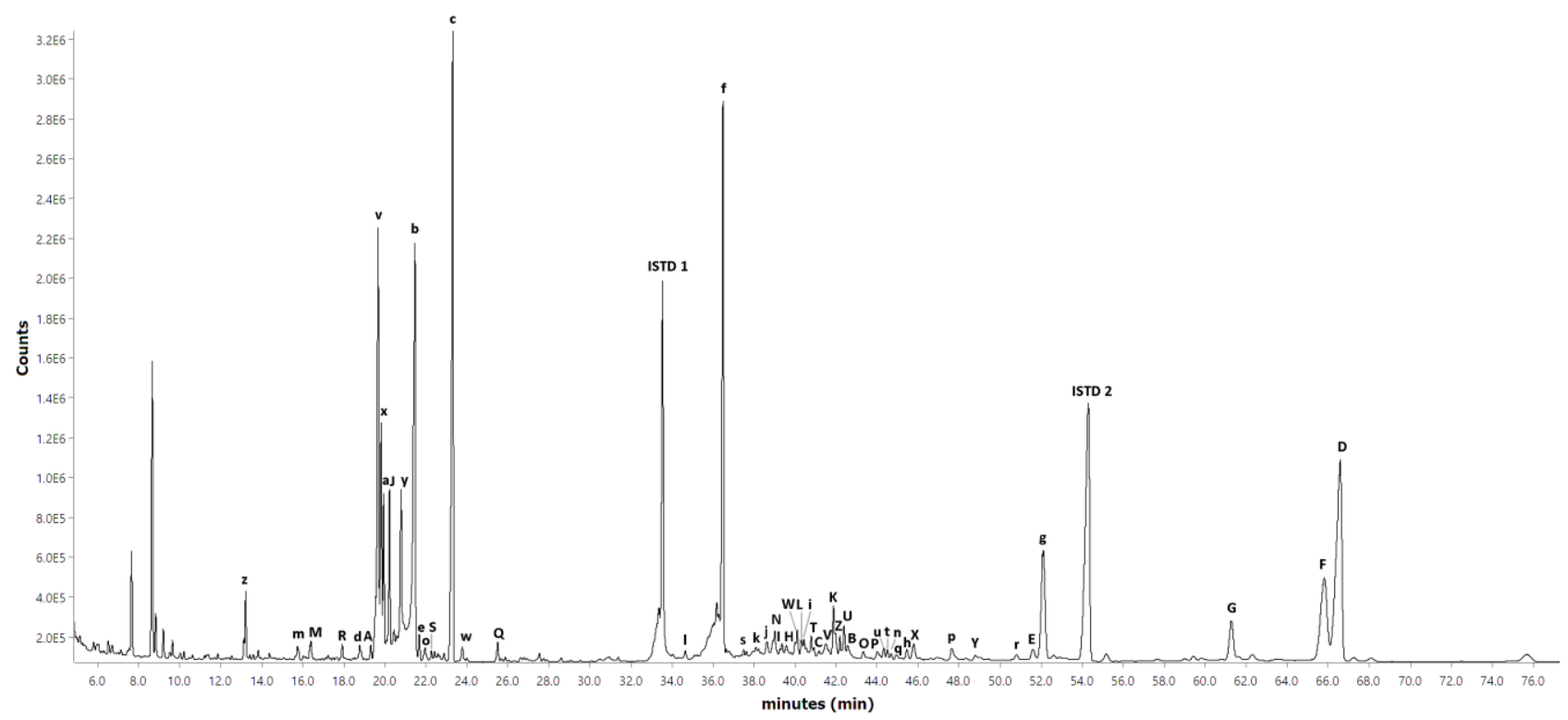

Figure A4. Reference gas chromatography with flame ionisation detection or mass spectrometry (GC-FID/MS) chromatogram for spruce bark water extract. For alphabetical peak symbols, see Table 4.

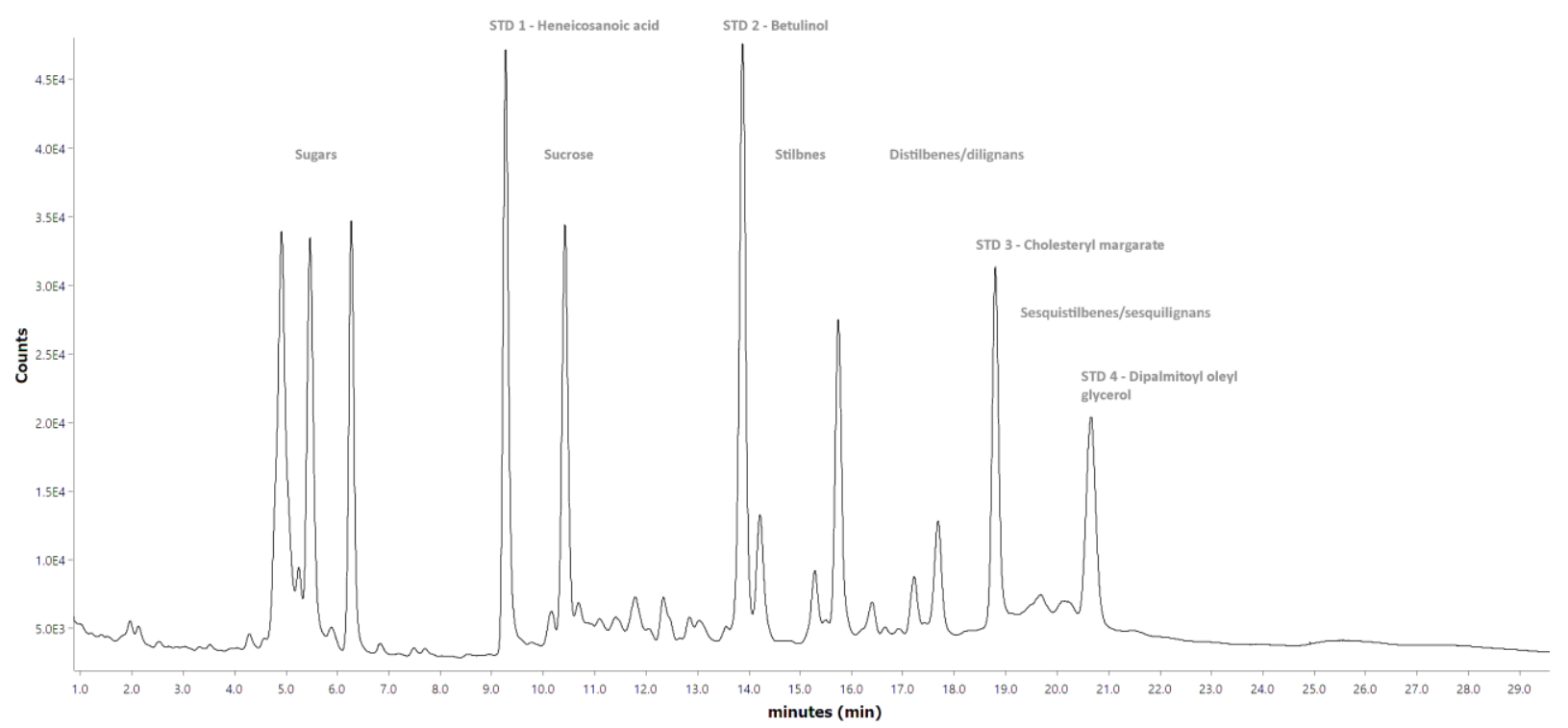

Figure A5. Reference gas chromatography with flame ionisation detector (GC-FID; short-column) chromatogram for spruce bark water extract. 


\section{Appendix B. Suggested Stilbenoid Structures}

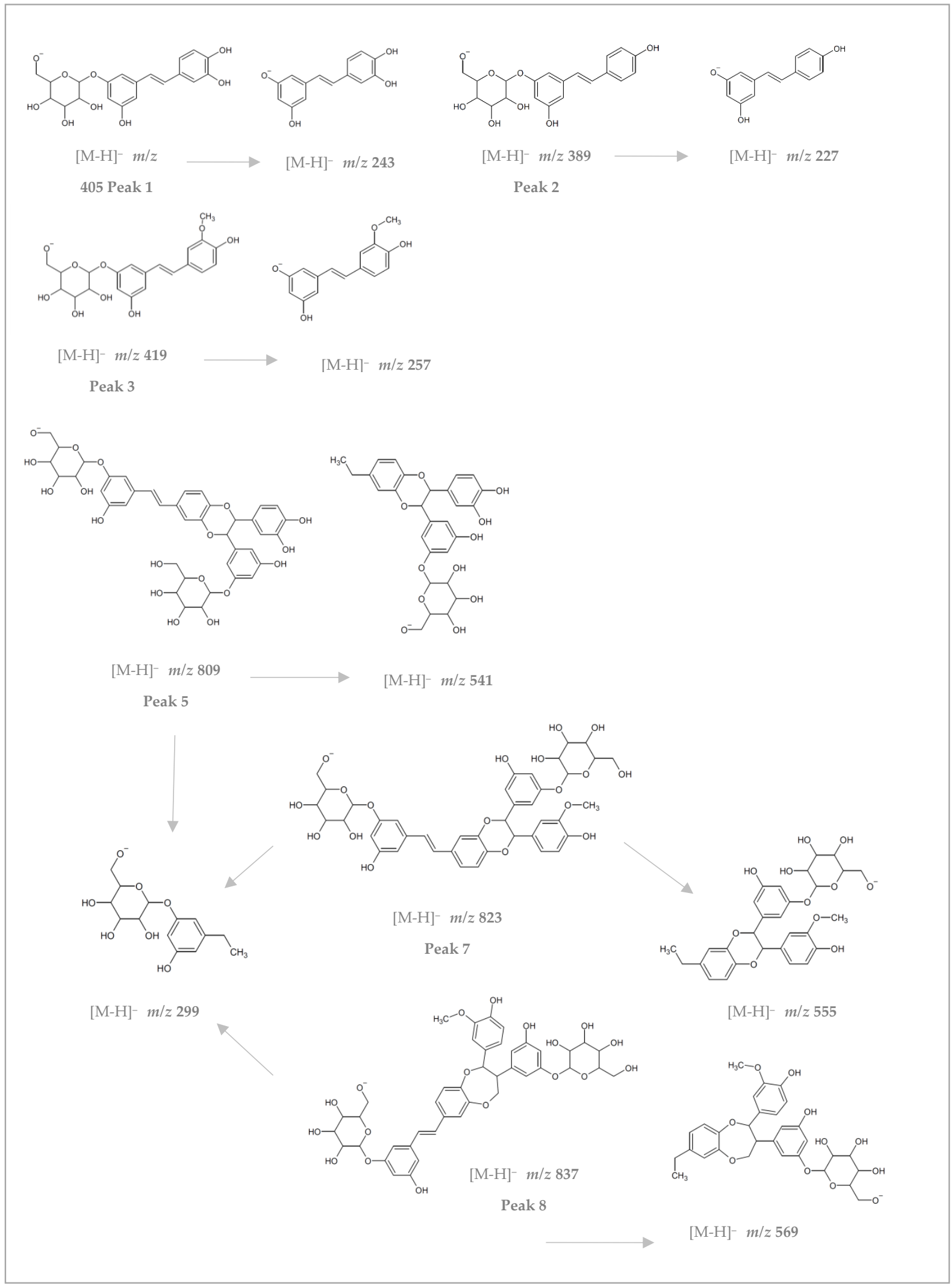

Figure A6. Suggested structures and fractionation of some detected compounds from the high-performance liquid chromatography (HPLC) analysis of bark hot-water extract. 


\section{References}

1. Kemppainen, K. Production of Sugars, Ethanol and Tannin from Spruce Bark and Recovered Fibres. Ph.D. Thesis, Aalto University, Espoo, Finland, 2015.

2. Mannila, E.; Talvitie, A. Stilbenes from Picea abies Bark. Phytochemistry 1992, 31, 3288-3289. [CrossRef]

3. Krogell, J.; Holmbom, B.; Pranovich, A.; Hemming, J.; Willför, S. Extraction and Chemical Characterization of Norway Spruce Inner and Outer Bark. Nord. Pulp Paper Res. J. 2012, 27, 6-17. [CrossRef]

4. Nurmi, J. Heating Values of Mature Trees. Acta For. Fenn. 1997, 256, 7517. [CrossRef]

5. Kimland, B.; Norin, T. Wood Extractives of Common Spruce, Picea-abies (L) Karst. Svensk Papperstidn. 1972, 75, $403-409$.

6. Alén, R. Structure and Chemical Composition of Wood. In Forest Products Chemistry; Stenius, P., Ed.; Fapet Oy: Helsinki, Finland, 2000; pp. 11-57.

7. Assarsson, A.; Croon, I. Studies on Wood Resin, especially the Change in Chemical Composition during Seasoning of the Wood, Part 1. Changes in the Composition of the Ethyl Ether Soluble Part of the Extractives from Birch Wood during Log Seasoning. Svensk Papperstidn. 1963, 21, 876-883.

8. Jirjis, R.; Theander, O. The Effect of Seasonal Storage on the Chemical Composition of Forest Residue Chips. Scand. J. For. Res. 1990, 5, 437-448. [CrossRef]

9. Ekman, R. Resin during Storage and in Biological Treatment. In Pitch Control, Wood Resin and Deresination; Back, E.L., Allen, L.H., Eds.; TAPPI Press: Atlanta, GA, USA, 2000; pp. 185-195.

10. Krigstin, S.; Wetzel, S. A Review of Mechanisms Responsible for Changes to Stored Woody Biomass Fuels. Fuel 2016, 175, 75-86. [CrossRef]

11. Fuller, W.S. Chip Pile Storage-A Review of Practices to Avoid Deterioration and Economic Losses. TAPPI J. 1985, 68, 48-52.

12. Kain, G.; Stratev, D.; Tudor, E.; Lienbacher, B.; Weigl, M.; Barbu, M.; Petutschnigg, A. Qualitative Investigation on VOC-Emissions from Spruce (Picea abies) and Larch (Larix decidua) Loose Bark and Bark Panels. Eur. J. Wood Wood Prod. 2020, 78, 403-412. [CrossRef]

13. Strömvall, A.; Petersson, G. Monoterpenes Emitted to Air from Industrial Barking of Scandinavian Conifers. Environ. Pollut. 1993, 79, 215-218. [CrossRef]

14. Eaton, R.A.; Hale, M. Staining Fungi and Moulds. In Wood: Decay, Pests and Protection, 1st ed.; Chapman \& Hall: London, UK, 1993; pp. 130-145.

15. Kallioinen, A.; Vaari, A.; Rättö, M.; Konn, J.; Siika-aho, M.; Viikari, L. Effects of Bacterial Treatments on Wood Extractives. J. Biotechnol. 2003, 103, 67-76. [CrossRef]

16. Josefsson, P.; Nilsson, F.; Sundström, L.; Norberg, C.; Lie, E.; Jansson, M.B.; Henriksson, G. Controlled Seasoning of Scots Pine Chips using an Albino Strain of Ophiostoma. Ind. Eng. Chem. Res. 2006, 45, 2374-2380. [CrossRef]

17. George, B.; Suttie, E.; Merlin, A.; Deglise, X. Photodegradation and Photostabilisation of Wood-the State of the Art. Polym. Degrad. Stab. 2005, 88, 268-274. [CrossRef]

18. Mallory, F.B.; Mallory, C.W. Photocyclization of Stilbenes and Related Molecules. Org. React. 2004, 30, 1-456.

19. Zahri, S.; Belloncle, C.; Charrier, F.; Pardon, P.; Quideau, S.; Charrier, B. UV Light Impact on Ellagitannins and Wood Surface Colour of European Oak (Quercus petraea and Quercus robur). Appl. Surf. Sci. 2007, 253, 4985-4989. [CrossRef]

20. Olsson, V. Wet Storage of Timber: Problems and Solutions. Master's Thesis, Industrial Ecology Royal Institute of Technology, Stockholm, Sweden, 2005.

21. Lang, A.H.; Mendell, B.C. Sustainable Wood Procurement: What the Literature Tells Us. J. For. 2012, 110, 157-163. [CrossRef]

22. Hedmark, Å.; Scholz, M. Review of Environmental Effects and Treatment of Runoff from Storage and Handling of Wood. Bioresour. Technol. 2008, 99, 5997-6009. [CrossRef] [PubMed]

23. Ekman, R.; Hafizoglu, H. Changes in Spruce Wood Extractives due to Log Storage in Water. In Proceedings of the Seventh International Symposium on Wood and Pulping Chemistry, Beijing, China, 25-28 May 1993; pp. 25-28.

24. Jirjis, R. Effects of Particle Size and Pile Height on Storage and Fuel Quality of Comminuted Salix viminalis. Biomass Bioenerg. 2005, 28, 193-201. [CrossRef]

25. Jyske, T.; Brännström, H.; Sarjala, T.; Hellström, J.; Halmemies, E.; Raitanen, J.; Kaseva, J.; Lagerquist, L.; Eklund, P.; Nurmi, J. Fate of Antioxidative Compounds within Bark during Storage: A Case of Norway Spruce Logs. Molecules 2020, 25, 4228. [CrossRef] [PubMed]

26. Anerud, E.; Routa, J.; Bergström, D.; Eliasson, L. Fuel Quality of Stored Spruce Bark-Influence of Semi-Permeable Covering Material. Fuel 2020, 279, 118467. [CrossRef]

27. Bianchi, S.; Koch, G.; Janzon, R.; Mayer, I.; Saake, B.; Pichelin, F. Hot Water Extraction of Norway Spruce (Picea abies [Karst.]) Bark: Analyses of the Influence of Bark Aging and Process Parameters on the Extract Composition. Holzforschung 2016, 70, 619-631. [CrossRef]

28. Venäläinen, A.; Tuomenvirta, H.; Pirinen, P.; Drebs, A. A Basic Finnish Climate Data Set 1961-2000-description and Illustrations. Finn. Meteorol. Inst. Rep. 2005, 5, 1-27.

29. Nurmi, J.; Hillebrand, K. The Characteristics of Whole-Tree Fuel Stocks from Silvicultural Cleanings and Thinnings. Biomass Bioenerg. 2007, 31, 381-392. [CrossRef] 
30. European Committee for Standardization (CEN). Solid Biofuels—Methods for the Determination of Moisture Content-Oven Dry Method_Part 2: Total Moisture-Simplified Method; CEN/TS 14774-2: 2004; European Committee for Standardization: Brussels, Belgium, 2004.

31. Örså, F.; Holmbom, B. A Convenient Method for the Determination of Wood Extractives in Papermaking Process Waters and Effluents. J. Pulp Pap. Sci. 1994, 20, J361-J366.

32. Gabaston, J.; Richard, T.; Biais, B.; Waffo-Teguo, P.; Pedrot, E.; Jourdes, M.; Corio-Costet, M.; Mérillon, J. Stilbenes from Common Spruce (Picea abies) Bark as Natural Antifungal Agent Against Downy Mildew (Plasmopara viticola). Ind. Crops Prod. 2017, 103, 267-273. [CrossRef]

33. TAPPI Test Methods 222 om-02. Acid-insoluble lignin in wood and pulp. In 2002-2003 TAPPI Test Methods; TAPPI: Tokyo, Japan, 2002.

34. TAPPI Useful Methods 250. Acid-Soluble Lignin in Wood and Pulp. In 1991 TAPPI Useful Methods; TAPPI: Tokyo, Japan, 1991.

35. Swan, B. Isolation of Acid-Soluble Lignin from the Klason Lignin Determination. Svensk Papperstidn. 1965, 68, 791-795.

36. Bertaud, F.; Sundberg, A.; Holmbom, B. Evaluation of Acid Methanolysis for Analysis of Wood Hemicelluloses and Pectins. Carbohydr. Polym. 2002, 48, 319-324. [CrossRef]

37. Singleton, V.L.; Rossi, J.A. Colorimetry of Total Phenolics with Phosphomolybdic-Phosphotungstic Acid Reagents. Am. J. Enol. Vitic. 1965, 16, 144-158.

38. Bukhanko, N.; Attard, T.; Arshadi, M.; Eriksson, D.; Budarin, V.; Hunt, A.J.; Geladi, P.; Bergsten, U.; Clark, J. Extraction of Cones, Branches, Needles and Bark from Norway Spruce (Picea abies) by Supercritical Carbon Dioxide and Soxhlet Extractions Techniques. Ind. Crops Prod. 2020, 145, 112096. [CrossRef]

39. Murzin, D.; Holmbom, B. Analytical Approaches in the Catalytic Transformation of Biomass: What Needs to be Analyzed and Why? In Catalysis for the Conversion of Biomass and Its Derivatives, 1st ed.; Behrens, M., Datye, A.K., Eds.; Max Planck Institute for the History of Science: Berlin, Germany, 2013; pp. 183-211.

40. Varila, T.; Brännström, H.; Kilpeläinen, P.; Hellström, J.; Romar, H.; Nurmi, J.; Lassi, U. From Norway Spruce Bark to Carbon Foams: Characterization, and Applications. BioResources 2020, 15, 3651-3666.

41. Willför, S.M.; Smeds, A.I.; Holmbom, B.R. Chromatographic Analysis of Lignans. J. Chromatogr. A 2006, 1112, 64-77. [CrossRef]

42. Sjöström, E. Wood Chemistry: Fundamentals and Applications, 2nd ed.; Academic Press: San Diego, CA, USA, 1993.

43. Olm, L. Pitch Problems and their Control in Kraft Mills using Hardwoods from Temperate and Tropical Zones: A Literature Survey. Appita 1984, 37, 479-483.

44. Brand, M.A.; de Muñiz, G.I.B.; Quirino, W.F.; Brito, J.O. Storage as a Tool to Improve Wood Fuel Quality. Biomass Bioenerg. 2011, 35, 2581-2588. [CrossRef]

45. Roffael, E. Significance of Wood Extractives for Wood Bonding. Appl. Microbiol. Biotechnol. 2016, 100, 1589-1596. [CrossRef] [PubMed]

46. Ramachandran, S.; Fontanille, P.; Pandey, A.; Larroche, C. Gluconic Acid: Properties, Applications and Microbial Production. Food Technol. Biotechnol. 2006, 44, 185-195.

47. Li, S.; Niu, X.; Zahn, S.; Gershenzon, J.; Weston, J.; Schneider, B. Diastereomeric Stilbene Glucoside Dimers from the Bark of Norway Spruce (Picea abies). Phytochemistry 2008, 69, 772-782. [CrossRef]

48. Mulat, D.G.; Latva-Mäenpää, H.; Koskela, H.; Saranpää, P.; Wähälä, K. Rapid Chemical Characterisation of Stilbenes in the Root Bark of Norway Spruce by Off-line HPLC/DAD-NMR. Phytochem. Anal. 2014, 25, 529-536. [CrossRef] [PubMed]

49. Jyske, T.; Laakso, T.; Latva-Mäenpää, H.; Tapanila, T.; Saranpää, P. Yield of Stilbene Glucosides from the Bark of Young and Old Norway Spruce Stems. Biomass Bioenerg. 2014, 71, 216-227. [CrossRef]

50. Leigh, W.J.; Lewis, T.J.; Lin, V.; Postigo, J.A. The Photochemistry of 3,3',4,4'-Tetramethoxy- and 4-Hydroxy-3,3',4'Trimethoxystilbene-models for Stilbene Chromophores in Peroxide-Bleached, High-Yield Wood Pulps. Can. J. Chem. 1996, 74, 263-275. [CrossRef]

51. Mikulski, D.; Molski, M. Quantitative Structure-antioxidant Activity Relationship of Trans-Resveratrol Oligomers, Trans-4,4'Dihydroxystilbene Dimer, Trans-Resveratrol-3-O-Glucuronide, Glucosides: Trans-Piceid, Cis-Piceid, Trans-Astringin and TransResveratrol-4'-O- $\beta$-D-Glucopyranoside. Eur. J. Med. Chem. 2010, 45, 2366-2380. [PubMed] 